Reste der Urüberlieferung angeknüpft habe. Die ungeschichtliche Sage von Lào-tsè, welche Stan. Julien mittheilt, und welche von Wanderungen des chinesischen Weisen in den fernsten Westen wissen will, kann der verbürgten Geschichte gegenüber zwar nicht zur Erklärung herbeigezogen werden, wie dies A. Rémusat gethan, wohl aber beweiset sie, dafs auch den Chinesen der Gedanke eines Zusammenhanges Lào-tsè's mit fernwestlichen Einflüssen vorschwebte, und dieser Gedanke mufste doch irgendwie eine thatsächliche Veranlassung gehabt haben.

Dürfen wir aber einen solchen Zusammenhang, eine dadurch vermittelte Ueberlieferung annehmen, so ist es auch erklärlich, weshalb der hochheilige Name, der sicherlich nur als ein esoterisches Geheimnifs mitgetheilt war, auch nur so geheimnifsvoll angedeutet ist; weshalb Lào-tsè fast unmittelbar nach unserer Stelle versichert : „Immer und immer kann Er nicht (oder darf er nicht - pŭ kò, non potest, aber auch non vult, non licet) genannt werden. ${ }^{\circ}$ Dafs er einen, Seinem Wesen entsprechenden chinesischen Namen für Ihn nicht kannte und vergeblich suchte, zeigt Kap. 25.

V. von Straufs.

\title{
Die Aussprache des Hebräischen bei Hieronymus.
}

Untersucht von Carl Siegfried.

Die vorliegende Frage ist, so viel wir wissen, noch nicht selbständig behandelt worden. In der älteren Literatur ward sie meist wie bei Montfaucon, quomodo veteres interpretes hebraice legerint (zu Origenis, Hexapla II, 397 ff. bei Wolf, biblioth. hebr. II, p. 648-657) mit der Darstellung der Aussprache der LXX und der griechischen Kirchenväter verbunden und dadurch sowie durch 
unsystematische und unvollständige Behandlung verdunkelt. Später ward sie in textkritischer und textgeschichtlicher Rücksicht untersucht, in Folge dessen aber nur nach einer Seite hin erledigt. Auch drehte sich dabei die Untersuchung gewöhnlich immer um dieselben Beispiele. So im Streit zwischen Cappell us und Buxtorf (s. Schnedermann, die Controverse des Ludov. Cappellus mit den Buxtorfen 1879, S. 46-49), später in den wissenschaftlichen Arbeiten von Ge senius (Gesch. der hebr. Sprache 1815, S. 196-200), H upfel d (Beleuchtung dunkler Stellen in der alttestamentl. Textgeschichte in den theol. Studien u. Kritiken 1830 , S. 571-587) und neuerdings Nowack (die Bedeutung des Hieronymus für die alttest. Textkritik 1875, S. 6. 7).

Wir verfolgen den sprachgeschichtlichen Gesichtspunkt und halten uns dabei vorzugsweise an die in den auslegenden Werken des Hieronymus, sowie in den quaestiones hebraicae in Genesin vorliegenden Beispiele von hebräischen Worterklärungen, von denen wir hier zunächst einen alphabetischen Index aufstellen, für die nur gelegentlich herangezogenen Eigennamen auf die bereits in alphabetischer Ordnung gegebenen Onomastika des Hieronymus (liber interpretationis hebraicorum nominum und liber de situ et nominibus locorum hebraicorum in Lagarde, onomastica sacra 1870. 71, I, p. $1-81$ und p. 82-160, cf. p. 204-206) und überhaupt auf den Index von Lagarde, a. a. O. II, p. 60-94 verweisend.

Wir citiren nach der Ausgabe des Hieron. von V allarsi 1766-72, die quaestiones hebr. nach der Ausgabe von Lagarde 1868.

\section{A.}

A ad quaestt. h. p. 50.51 nach der Schreibung Galaad = 7ִ? Gen.

$31,48$.

a a d quaestt. b. p. 66 Gen. 48, 22 7חญ.. 
a a dam IV, 43 D Jes. 2, 22 口7ฺำ.

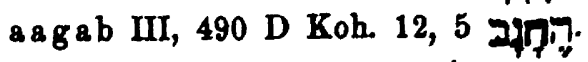

abal III, 386 D Koh. 1, 1. הָבר (constr.).

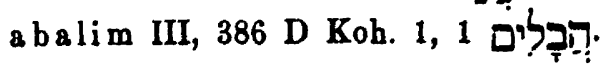

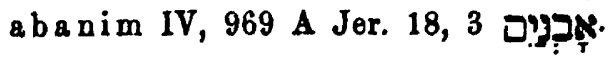

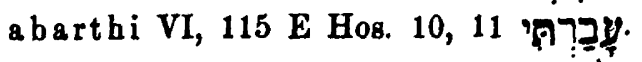

abdil VI, 811 E. 812 A Sach. 4, 10 הָכְּרִ

aben VI, $818 \mathrm{C}$ zu Sach. 5, 7 צֶ.

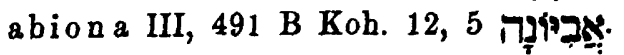

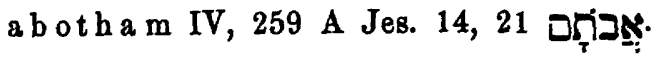

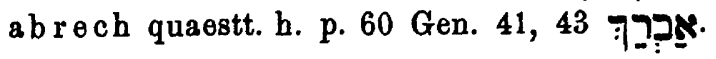

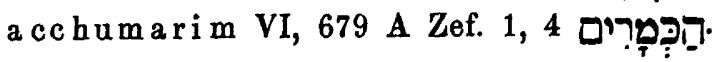

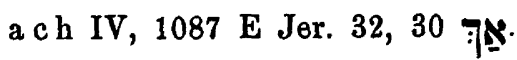

a chor IV, 781 C Jes. 65, 10. VI, 22 C Hos. 2, 17. 486 C zu Mi. 4,

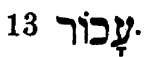

adadremmon VI, $904 \mathrm{C}$ Sach. 12, 11 דִּרִ

adagim VI, 685 D Zef. 1, 10 .

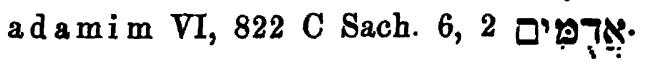

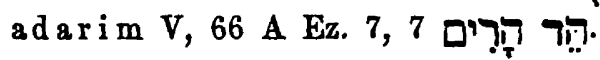

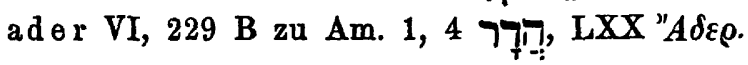

adonai IV, 107 C Jes. 7, 12. 346 A Jes. 26, 4. V, 616 B Ez. 48,

34. VI, $633 \mathrm{E}$ Hab. 3, 2 ִִּר

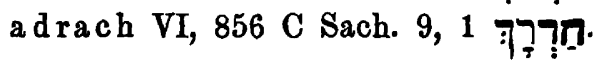

aela m V, 89 D Ez. 8, 16. 487 C zu Ez. 40, 36 ארָָּ

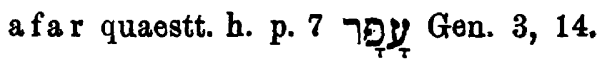

aganoth IV, 319 E Jes. 22, 24 תئis.

agg a IV, 206 C Jes. 19, 17 דִ

aggoi VI, 977 D Mal. 3, 9 19.

a gmon IV, 205 E. 294 E Jes. 19, 15 אְִִמטוֹן.

agor IV, 473 A Jes. 38, 14 7ูปע.

agur IV, 473 A Jes. 38, 14. 900 B Jer. 8, 7 עָּגוּר

a her IV, 509 E Jes. 42, 8 אֵחר.

a h u quaestt. h. p. 60 Gen. 41, 2 :

aiala quaestt. h. p. 70 Gen. 49, 21 ה

al VI, 631 B Hab. 3, 1 לע.

alamoth IV, 109 A Ps. 9, 1 ת עִ עִלמוֹ: 
ale V, 596 C Ez. 47, 12 กלקצ.

alechcha VI, $81 \mathrm{C}$ Hos. 8, 1 7.

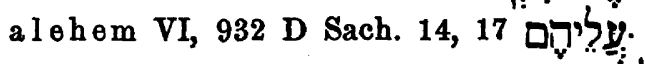

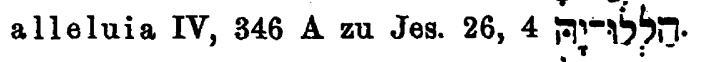

alluoth VI, 609 A Hab. 2, 2 תin' הִ-

alma IV, 108 E Jes. 7, 14 quaestt. h. p. 37 זִ

amaggenach VI, 128 D Hos. 11, 8 קי:

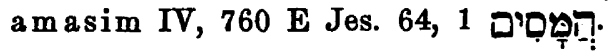

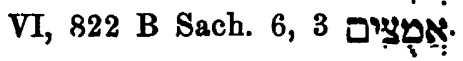

a mir IV, 196 A Jes. 17, 9 אָָמִיר

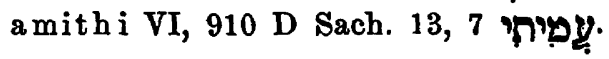

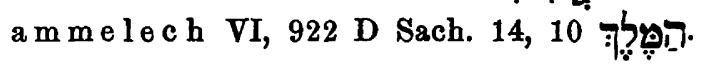

a m mi VI, 509 A Mi. 6, 16, quaestt. h. p. 31 Gen. 19, 83 עעפִי.

ammon VI, 675 B Zef. 1, 1 jî̀ș.

am on VI, 570 B Nah. 3, 8 אִָ

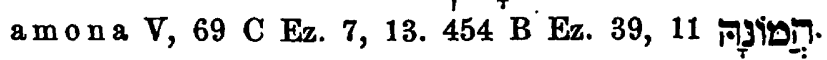

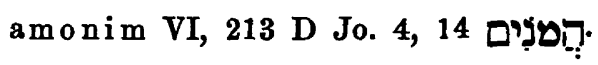

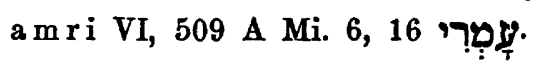

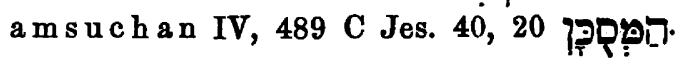

amun IV, 434 A Jes. 33, 3 jivi T.

an a IV, 461 B Jes. 37, 13 עมנ‥

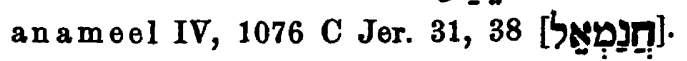

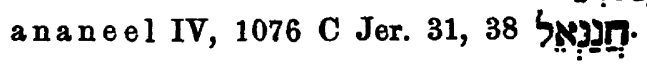

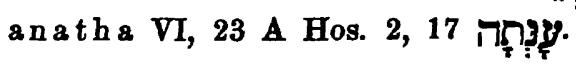

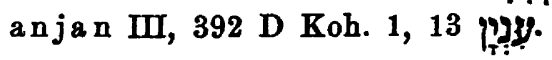

anie VI, 890 C Sach. 11, 11 igys:

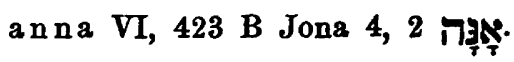

anus IV, 282 B Jes. 17, 11.960 A Jer. 17, 9 אבנוּ שִ.

a pedno V, 722 A Dan. 11, 45 1970x.

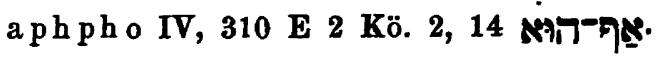

VI, 235 E Am. 1, 11 iפs.

ar IV, 184 C Jes. 15, 1 רִ.

ara VI, 424 A Jon. 4, 4 דָ דָרָ.

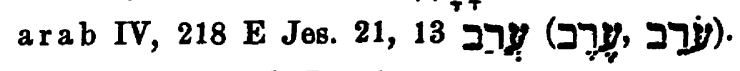

arabe IV, 857 C Jer. 3, 2 עำ:

arabim IV, 188 A Jes. 15, 7 ערקבים: 
s rasth om VI, 118 D Hos. 10, 13 פดุ

a r a z IV, 991 B Jer. 22, 15 int.

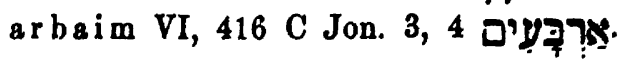

a r be VI, $145 \mathrm{E}$ zu Hos. 13, 3 กฺุ

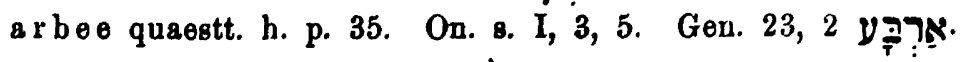

arbel VI, 120 D Hos. 10, 14 לxาำ.

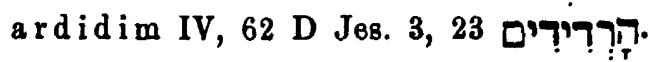

areb VI, 910 C Dach. 13, 7 בתק

arellam IV, 435 B Jes. 33, 7 אִקר?

ares IV, 273 A. 289 A Jes. 19, 18 Еา7?.

n IV, $207 \mathrm{~B} \quad$ n "

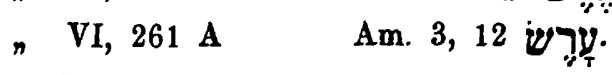

arethic V, 76 E Ez. 7, 23 קדריד

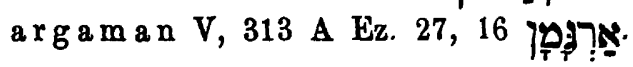

aria IV, 216 A Jes. 21, 8 :ארי:

arie IV, 305 A Jes. 21, 8 אִרי.

ariel IV, 388 D Jes. 29, 1. V, 528 D Ez. 43, 15 אִרִריאִי.

arim IV, 180 A Jes. 14, 21 עִ עִרים.

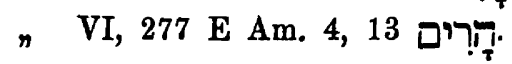

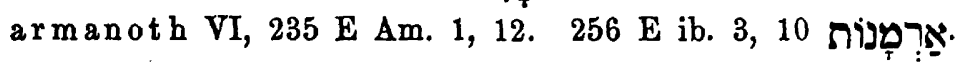

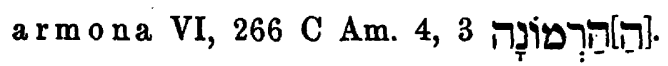

arsoth VI, 226 B Am. 1, 3 กiצ? ?ִ?

as VI, $57 \mathrm{C}$ Hos. 5, 12 שै.

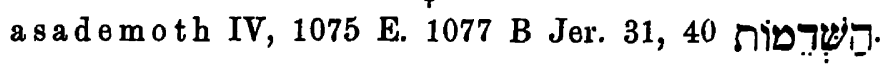

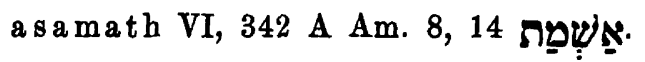

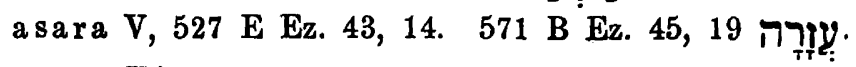

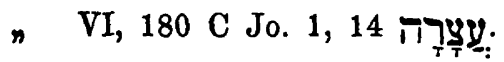

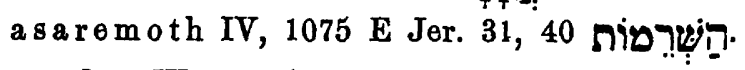

asedec IV, 207 A zu Jes. 19, 18 קצר.

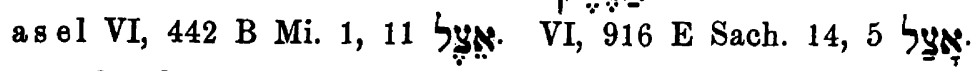

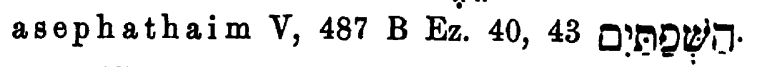

aser IV, 43 D Jes. 2, 22 אְִּׁ.

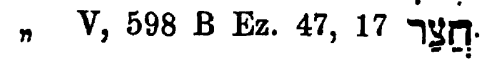

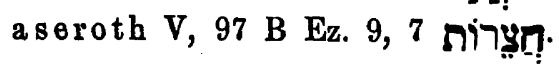

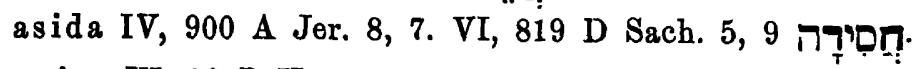

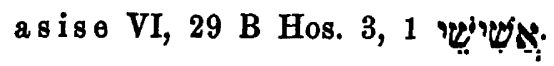


assur VI, 256 E zu Am. 3, 9 אמוּא.

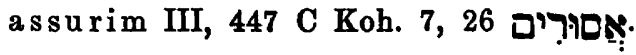

as te V, 492 E Ez. 40, 49 עy

ataroth VI, 827 B Sach. 6, 11 תiาำ:

at e moth V, 475 D Ez. 40, 16 תivpẹ:

a va IV, 461 B Jes. 37, 13 עִ עִדּה

aven VI, 227 D Am. 1, 5 אָד

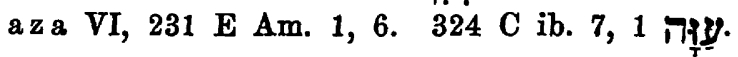

azael VI, 229 B Am. 1, 4 לำ.

azara V, 527 E Ez. 43, 17. 571 B ib. 45, 19 עעזרד:

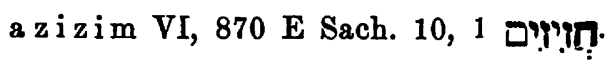

azuba IV, 739 E Jes. 62, 4 עִעוּרָ

B.

B a a 1 VI, 24 D zu Hos. 2, 18 לע.

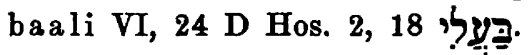

ba aphpho IV, 43 D Jes. 2, 22 골.

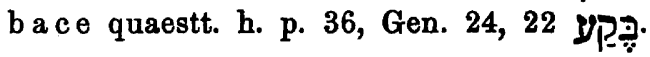

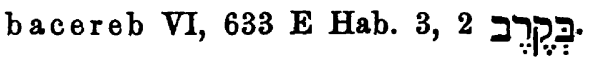

b ad VI, 903 A Sach. 12, 12 ๆอ.

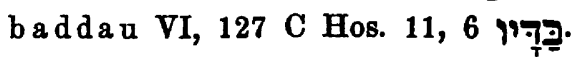

baddim V, 93 A. 589 D Ez. 9, 2. 697 D Dan. 10, 5. VI, 903 A zu

Sach. 12, 12 글.

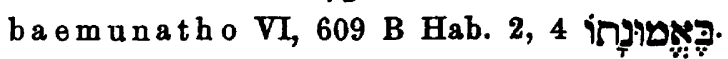

b a g a d quaestt. h. p. 46, Gen. 30, 11 7ุจุำ.

baggoim VI, 593 E Hab. 1, 5 밀.

b a hem quaestt. h. p. 22 zu Gen. 14, 5 פכד

bahem quaestt. h. p. 22 zu Gen. 14, 5 פִדְ [wobei H. voraussetzt,

dafs letzteres sich von dem vorhergehenden dadurch unterscheide, dafs es mit Chet geschrieben werde cf. p. 23, 1-3].

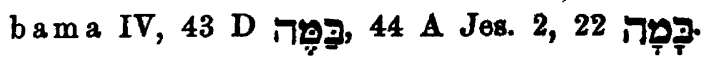

bamma IV, 44 A Jes. 2, 22 กำำ.

bamoth IV, 897 B Jer. 7, 31. $957 \mathrm{E}$ ib. 17, 3. $1089 \mathrm{E}$ ib. 32, 35.

V, 161 C Ez. 16, 16. VI, 328 D Am. 7, 9 กiฉอ̣.

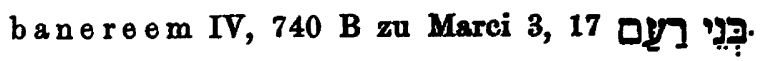

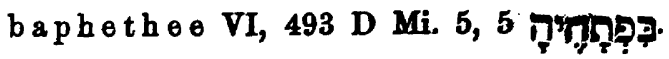




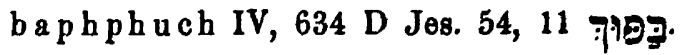

b a r VI, 903 B zu Sach. 12, 12 ๆฏ.

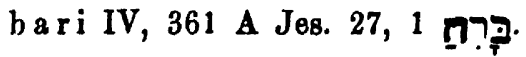

barihim IV, 519 B Jes. 43, 14 פרדּר

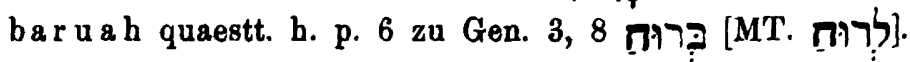

barura VI, 724 B Zef. 3, 9 בְּרוּרָה

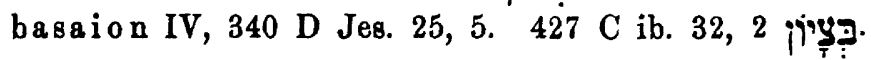

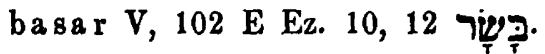

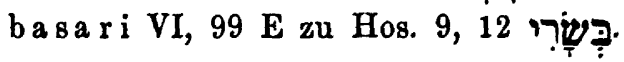

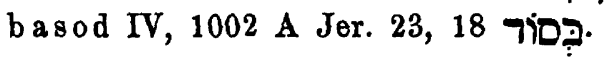

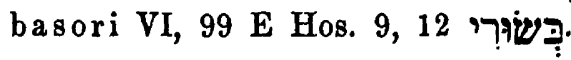

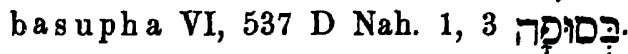

bath V, 563 D Ez. 45, 11 פַּ (das Mafs). VI, 487 A Mi. 4, 14 בַת (Tochter).

bau IV, 1087 D Jer. 32, 29 มูก

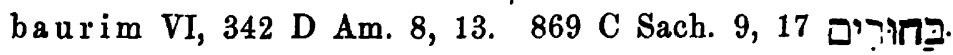

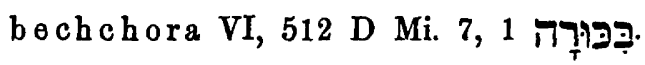

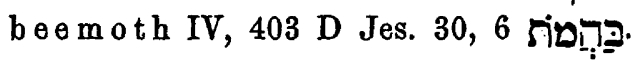

been IV, 430 A Jes. 32, 14 כַּ.

bel VI, 24 D zu Hos. 2, 18 בֶ.

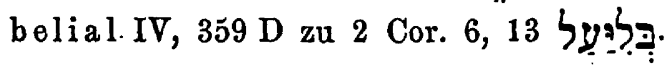

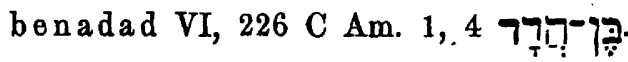

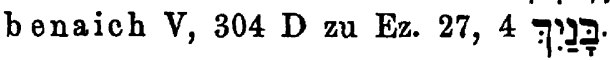

ber quaestt. b. p. 32, Gen. 21, 31 בְֵּ

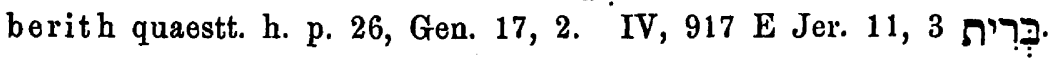

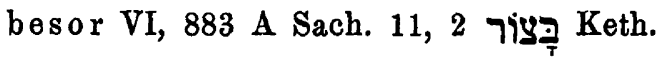

bete quaestt. h. p. 54 Gen. 34, 25 בְּ?

beth IV, 75 A Jes. 5, 10. 152 D Jes. 10, 30 ב.. VI, 334 D Am. 7

16 פיביה.

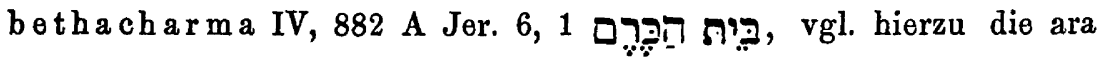
mäische Schreibung

bethi quaestt. h. p. 25 Gen. 15, 2 בֶיתִ

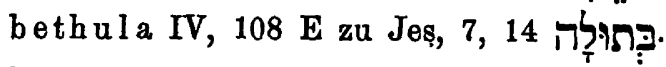

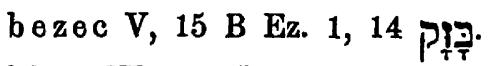

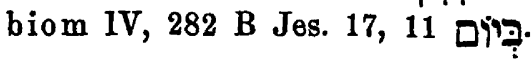

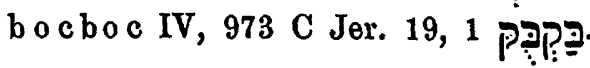


b ocer VI, 333 E Am. 7, 14 כּוֹק

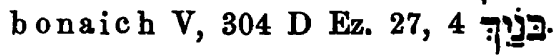

bor IV, 883 E Jer. 6, 7 רפּ.

borith IV, 850 C Jer. 2, 22. VI, 972 E Mal. 3, 2 בּרִ.

borodim VI, 823 A Sach. 6, 3 פְרִרִּים

bos or IV, $442 \mathrm{D}$ zu Jes. 34, 6 כָרָּ

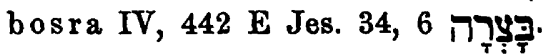

bresith quaestt. h. p. 3 Gen. 1, 1 בְרָראשִׁית.

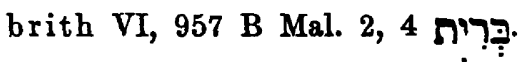

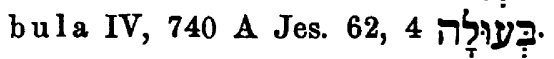

bus V, 313 A Ez. 27, 16 ב.ּ.

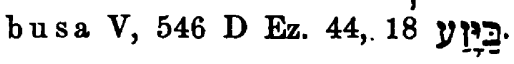

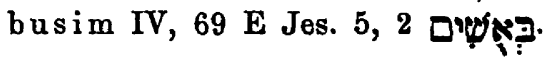

o.

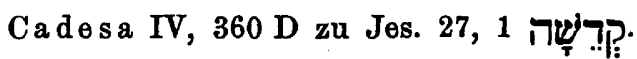

cadesim VI, $41 \mathrm{E}$ zu Hos. 4, 14 שקריש:

cadeso IV, 753 A Jes. 63, 10 קp:

cadesoth VI, 41 A. D Hos. 4, 14 תifi:

cadim V, 321 A Ez. 27, 26 קרִקים

cadisin V, 646 B Dan. 4, 6 קִקר?

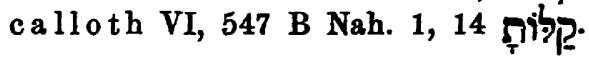

canani VI, 481 D Prov. 8, 22 קָקרנָ (Pausa).

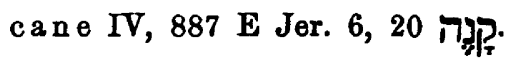

canithi quaestt. h. p. 8 Gen. 4, 1 קָנירית

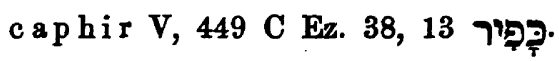

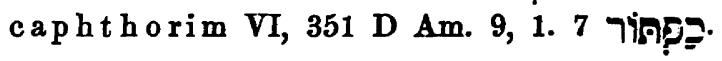

carae VI, 226 D eu Am. 1, 5 קִּרִ

carath IV, 843 C Jer. 2, 2. 860 A Jer. 3, 12. 973 E Jer. 19, 2

קָקרז

carathi IV, 110 C Je8. 7, 14 ת קרזד

c aria IV, 346 D Jes. 26, 5 cf. p. $388 \mathrm{C}$.קר:קיד:

cariath VI, 18 D zu Hos. 2, 15 תקר?

casa IV, 360 D Jes. 27, 1 ip.

casleu VI, 832 A Sach. 7, 1 כִִּ כ.

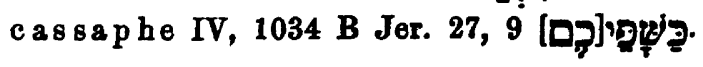


ca u IV, 378 A Jes. 28, 10 ip.

c edem V, 285 D. 286 A Ez. 25, 4 פקר.ק.

cona V, 84 A Ez. 8, 3 mरৃțp.

cesath V, 94 B Ez. 9, 2 קp:

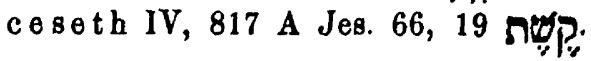

chabod IV, 161 C Jes. 11, 10. VI, 947 A Mal. 1, 6 רิจฺุ.

ch a char VI, 818 C Sach. 5, 7 פִכַּר.

chaesu VI, 910 A zu Sach. 13, 4 1E' ?כ?

chalanno IV, 143 B Jes. 10, 9 כִִּ

chaneser IV, 179 B. 255 D Jes. 14, 19 כִּנִצִּר

chaphir V, 449 C Ez. 38, 13 פְּפקיר.

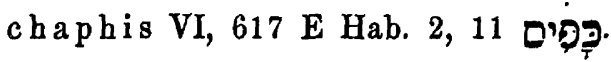

c h a phphe IV, 294 E Jes. 19, 15 כִּุ.

c hasab IV, 380 B Jes. 28, 17 כָכָุ.

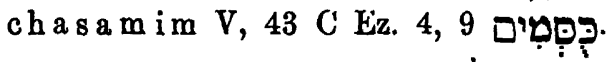

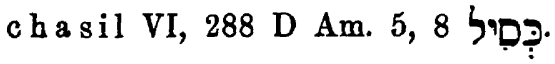

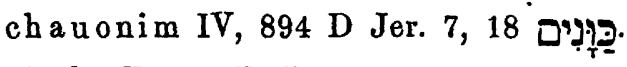

cheb IV, 389 D Jes. 29, 4 בִִּּ

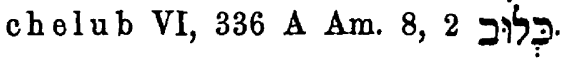

chen VI, 890 C Sach. 11, 11 i⿱⺈.⺕亅

chermel IV, 397 A Jes. 29, 17. 845 D Jer. 2, 7. VI, 225 D Am.

1, 2 כִ כְ:

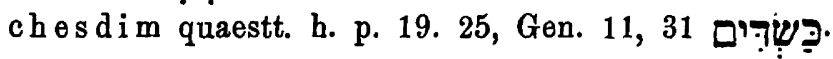

chethim V, 716 C Dan. 11, 30 כִִִּים.

chetim IV, 321 A Jes. 23, 1.

chi IV, 43 D Jes. 2, 22. VI, 547 B Nah. 1, 14 .

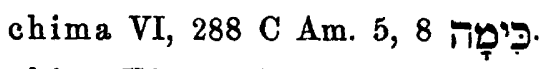

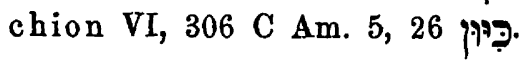

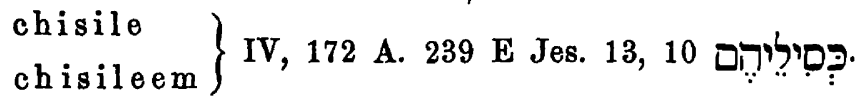

chocab VI, 305 C Am. 5, 26 כִּุ

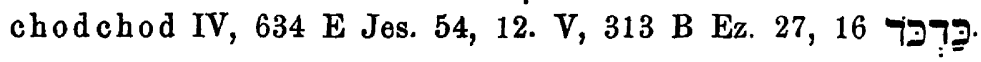

chores IV, 532 B Jes. 45, 1 כִ כִ.

chorethim V, 293 D Ez. 25, 16. VI, 700 E Zef. 2, 5 כִּרִחִים.

chullo V, 109 D Ez. 11, 15 כִכלְ:

ciceion IV, 131 A. VI, 425 E Jon. 4, 6 קיפקיקוין. 
cir IV, 467 D Jes. 38, 2. V, 127 D Ezz. 13, 12. VI, 351 A Am. 9, 7 קיריר.

cira VI, 226 D Am. 1, 5 קירדה

c isoa IV, 376 A Jes. 28, 8 קיז איר

codes IV, 600 D Jes. 52, 1 i.

cods a IV, $485 \mathrm{C}$ zu Jes. 40, 13 אקד

colea IV, 915 B Jer. 10, 18 ער.ק

c u e V, 266 C Ez. 23, 23 עip.

D.

D a ath III, 452 B zu Koh. 8, 6 ת를.

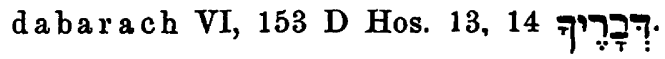

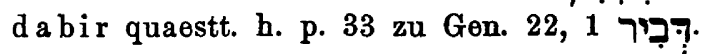

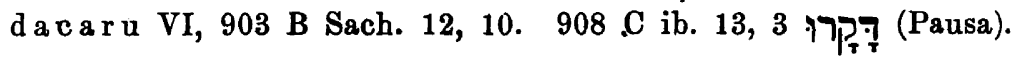

dag VI, 405 B Jon. 2, 1 גד్ק.

dajoth IV, 444 E Jes. 34, 15 กำชุ.

dame IV, 471 B Jes. 38, 10 רִִּ

d eah IV, 379 B Jes. 28, 9 העִ?

debbora V, 158 D zu Ez. 16, 13 הרְּר

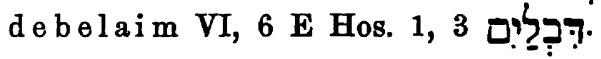

deber VI, 640 E Hab. 3, 4 דִִּ

deror V, 581 C Ez. 46, 17 דְר

doc IV, 488 C Jes. 40, 22 ר.

dodach IV, 1079 B Jer. 32, 7 ๆ רוֹרְ.

dodi IV, 1079 E Jer. 32, 8 רִi

dodim V, 150 C Ez. 16, 8 7.

d ou IV, 120 D zu Jes. 8, 9 דִע

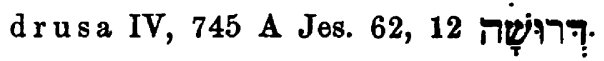

E.

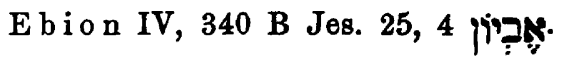

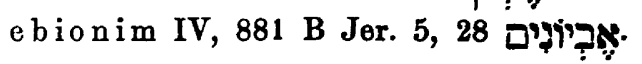

ebir IV, 1089 D Jer. 32, 35 שִ

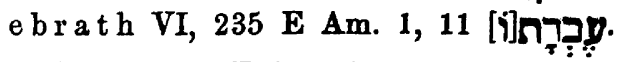

ecda IV, $634 \mathrm{E}$ Jes. 54, 12 ח7़ि:ק.

e c e b VI, $277 \mathrm{C}$ Am. 4, 12 עיעקב.

eddecel V, 727 C zu Dan. 12, 5 5ק.ק? 
eddim IV, 762 C Jes. 64, 5 עקים.

edel IV, 472 A Jes. 38, 11 ל7ก.

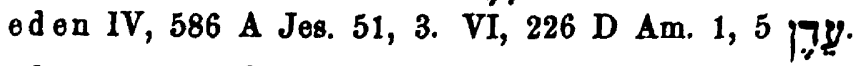

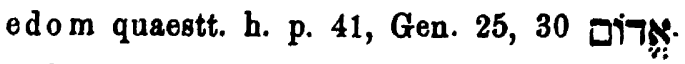

eobor VI, 298 C Am. 5, 17 Tap.

eelim IV, 109 B 2 Kö. 4, 27 הקצמצים

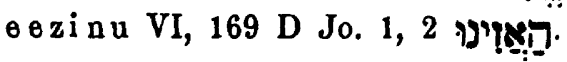

$\left.\begin{array}{l}\text { e fran } \\ \text { ef ron }\end{array}\right\}$ quaestt. h. p. 36. Gen. 23, 8 עִפְרוֹן

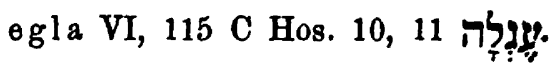

eje VI, 932 D Sach. 14, 17 יריקירית.

ei s quaestt. h. p. 52. Gen. 32, 29 צִ

el quaestt. h. p. 52. Gen. 32, 29. IV, 133 A Jes. 9, 5 אي. V, 475 D

Ez. 40, 14 איל

elai IV, 306 D Jes. 21, 11 אִלִי

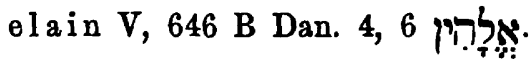

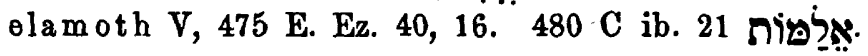

el a u V, 480 C Ez. 40, 21. 24 șילָ.

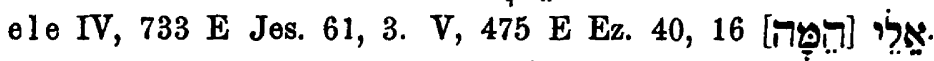

eled IV, 472 A zu Jes. 38, 11 חֶלֶר.

eli IV, 306 E zu Jes. 21, 11.

elil IV, 251 B Jes. 14, 12 הֵילת.

elim V, 475 C Ez. 40, 14 יצילים

elion IV, 45 A Ps. 87, 5 עִ עִלִיוּן

ella IV, 855 D Jer. 2, 34 אִלְלה

eloah VI, 277 E Am. 4, 12 פish.

eloim quaestt. h. p. 11, Gen. 6, 2 .

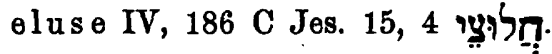

emec VI, 22 C Hos. 2, 17. 486 C Jos. 7, 26 עֵמקִ

e m mer IV, 977 E Jer. 20, 1 אִֵּר.

emmunim IV, 344 C Jes. 26, 2 אִמְ

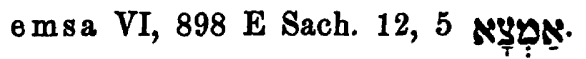

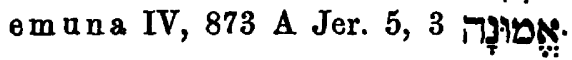

en ach VI, 328 A Am. 7, 7 꼬ำ.

enaim quaestt. h. p. 58, Gen. 38, 14 עִיעִ

enam VI, 818 A Sach. 5, 6 עיצָם 


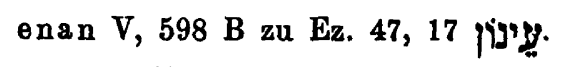

F siehe $\mathrm{Ph}$.

F ar a quaestt. h. p. 26, Gen. 16, 12 פקֶ?

Finees psalterium iuxta Hebraeos Hier. ed. Lagarde p. 113, Ps.

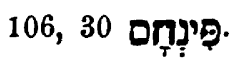

G.

G a b V, 527 D Ez. 43, 13 2g.

gader V, 513 D Ez. 42, 7 77g.

gadol VI, 405 B Jon. 2, 1 לị̄?.

gal quaestt. h. p. 50, Gen. 31, 46. 47 hs.

galila V, 591 B Ez. 47, 8 Tr.

galiloth VI, 210 A Jo. 4, 4 הiליל?

gallim IV, 152 D Jes. 10, 30. VI, 141 A Hos. 12, 12 .

gamadim V, 309 E Ez. 27, 11 יㅜ감. 


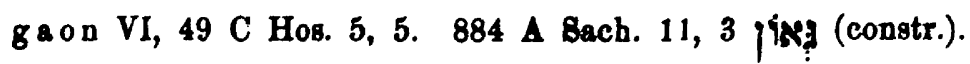

$\mathrm{g}$ a r VI, $700 \mathrm{E} \mathrm{zu} \mathrm{Zef.} \mathrm{2,} 5$ 7f.

gazaroni V, 631 D Dan. 2, 27 ירוֹ

gazera V, 509 E. 510 D Ez. 42, 10 กิ7ฺ?

ge IV, 371 E Jes. $28,1 . \nabla, 453$ E Ez. 39, 15 (constr.).

n IV, 850 E Jer. 2, 23 איב:

gebal V, 321 E zu Ez. 27, 27 לִ

geber IV, 318 D Jes. 22, 17 קֶּקר

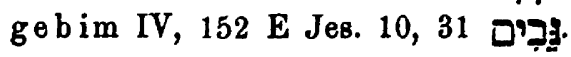

gebira IV, 935 A Jer. 13, 18 gְרִירָּר

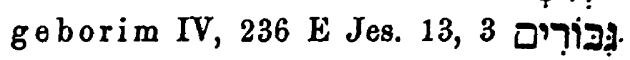

gebul VI, 383 D zu Obdj. 20 ํㅣำ.

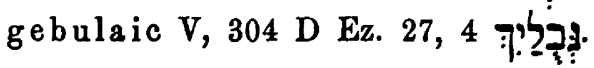

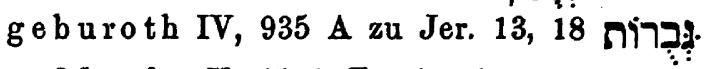

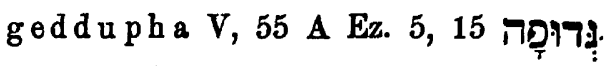

gedud VI, 487 A Mi. 4, 14 과ำำ.

geennom IV, 897 C Jer. 7, 31. 974 E Jer. 19, 6. 1089 D Jer. 32,

35 ם

gelgel V, 103 A Ez. 10, 13 ș

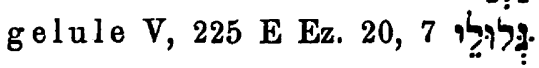

ger IV, 247 B Jes. 14, 1 רֶ.

gese m quaestt. h. p. 62, Gen. 45, 10 iשg.

n VI, 932 D Sach. 14, 17 每.

gesen quaestt. h. l. c. שֶ:

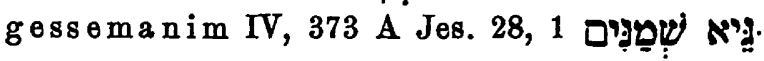

geth IV, 748 C Jes. 63, 2. VI, 443 C Mi. 1, 10 ถู.

geza IV, 155 D Jes. 11, 1 ע]

gezem VI, 170 E Jo. 1, 4 뮤.

gibbor IV, 133 B Jes. 9, 5. 148 D Jes. 10, 21. 1082 E Jer. 32, 18

רiอง.

gob V, 166 B Ez. 16, 24 ב⿱亠

goder IV, 698 E Jes. 58, 12 77.

goel IV, 713 C Jes. 59, 20 ئ.

goi VI, 700 E Zef. 2, 5 i

g o mer VI, 6 D. E Hos. 1, 3 s.

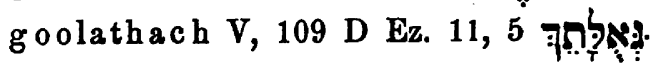


gozi VI, 324 C Am. 7, 1 भig.

gubba IV, 883 E zu Dan. 6, 8 ำ

H.

Hаја VI, $730 \mathrm{C} \mathrm{zu} \mathrm{Zef.} \mathrm{3,} 18$ דָּד

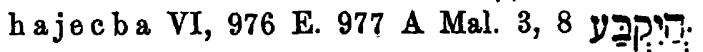

haium quaestt. h. p. 6, Gen. 3, 8 פהָ.

h a m m IV, 336 C Jes. 24, 23. 414 E Jes. 30, 26 กฺุ

h an a IV, 388 D Jes. 29, 1 חדָ.

hareb VI, 710 A Zef. 2, 14. 749 A Agg. 1, 11 כ כִก.

harsith IV, 973 C Jer. 19, 2 חַרדסיר Qeri.

barus VI, 213 D Jo. 4, 14 דุ.

hasil VI, 51 A Jo. 1, 4 דृ.

batath quaestt. b. p. 9, Gen. 4, 7 กאఱึ.

hazon VI, 611 D Hab. 2, 2 jim.

hechin VI, 277 E Am. 4, 12 הכפון.

hedalu IV, 43 D Jes. 2, 22 חִרְרוֹ.

heieu VI, 633 E Hab. 3, 2 ה ח.

helb on V, 316 A Ez. 27, 18 .

helem VI, 828 C zu Sach. 6, 10 חְל

hem IV, 1058 E zu Jer. 31, 2 व

hen IV, 1058 D Jer. 31, 2. VI, $828 \mathrm{C}$ zu Sach. 6, 10 j7.

herem V, 555 B Ez. 44, 29 חר.

heres IV, $336 \mathrm{C}$ zu Jes. 24, 23 הער.

hin V, 43 E Ez. 4, 11. 574 B Ez. 46, 5 . ד.

hir V, 647 C Dan. 4, עיר עיר 10.

his V, 127 C Ez. 13, 10 ח.

$n$ quaestt. h. p. 6, Gen. 2, 23 vix.

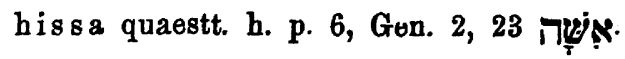

hod VI, 827 D Sach. 6, 13 7iר.

hodes VI, 51 A zu Hos. 4, 6 ff.

holed IV, 472 A zu Jes. 38, 11 7รुกु.

h o ma IV, 336 D zu Jes. 24, 23 กưin.

ก IV, 869 C Jer. 4, 19 กทุ่า.

homer V, 565 D Ez. 45, 13 חקת.

hores IV, 196 A Jes. 17, 9 שjing.

h u IV, 43 D Jes. 2, 22 ำ 
I.

J a IV, 346 A Jes. 26, 4 ד̦.

jabu IV, 1061 D Jer. 31, 9 יבאיָ

j a c c u m VI, 540 C Nah. 1, 6 יקוץ

jada u VI, 95 D Hos. 9, 7 ירו?

jad o VI, 640 B Hab. 3, 4 iדָ.

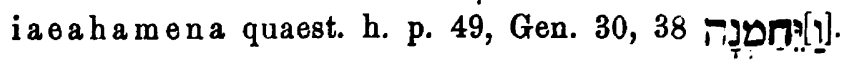

jaid IV, 889 C Jer. 6, 26 7ִיָ.

i a m in quaestt. h. p. 55 cfr. 56.57 zu Gen. 36, 24 מִ.

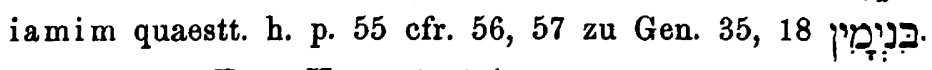

j a o VI, $741 \mathrm{E}$ zu Hagg. 2, 4 iก?

jar VI, 18, D Hos. 2, 15 עִ עִ.:

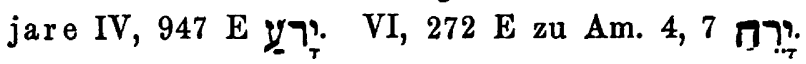

jaree IV, $336 \mathrm{D}$ zu Jes. 24, 23 ירָּ

jarib VI, 58 B Hos. 5, 13 ברי.

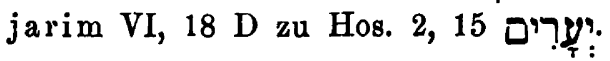

jasa VI, 793 E Sach. 2, 7 יצי

jasir IV, 880 C Jer. 5, 26 צשיר

jasub IV, 148 E Jes. 10, 21 יצשיר

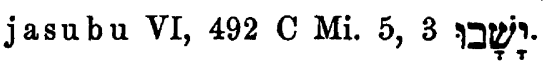

jathed IV, 320 C Jes. 22, 25 ?יחר:

idabber IV, 427 D Jes. 32, 6 ירביר

idid IV, $889 \mathrm{D}$ zu Jer. 6, 26 ירָריר

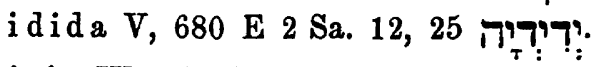

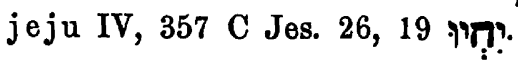

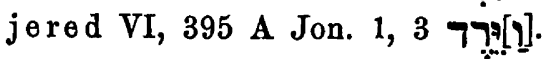

jeros VI, 118 D Hos. 10, 11 יֶרי

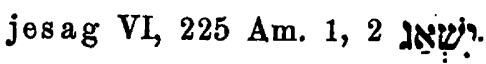

jeser IV, 345 A Jes. 26, 3 יִִּ

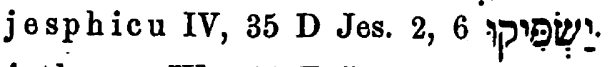

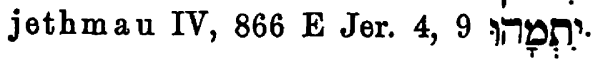

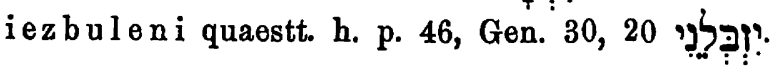

jeze V, 546 D zu Ez. 44, 18 עy?:

igar quaestt. h. p. 50, Gen. 31, 47 7d?:

iim IV, 175 A. 245 D Jes. 13, 22. 444 D Jes. 34, 14 אִים

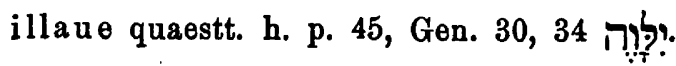


ioes IV, 133 A Jes. 9, 5 pyif.

ior IV, 230 A Jes. 23, 10 ראי:

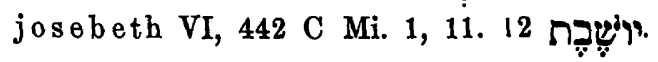

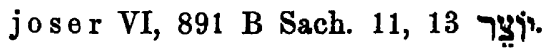

ir IV, 346 D zu Jes. 26, עיר שיר.

is IV, 840 B Gen. 2, 23. VI, 24 E Hos. 2, 18 אִיש.

n quaestt. b. p. 46 zu Gen. 30, 18 שุ...

is a a C VI, 334 D Am. 7, 16 ישֶ?

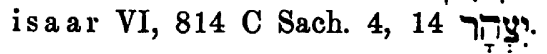

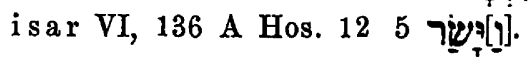

is s a IV, 840 B Gen. 2, 23. VI, 24 E zu Hos. 2, 18 אִ

is s i VI, 24 E Hos. 2,

is urun IV, 524 D Jes. 44, 2 קריפ:

L.

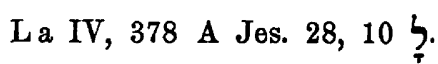

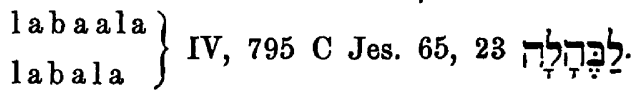

labana IV, 336 D Jes. 24, 23414 E Jes. 30, 26 לברזָ

la c VI, 424 A Jon. 4, 4 漯.

lacerath VI, 277 E Am. 4, 12 לקר?

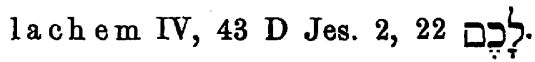

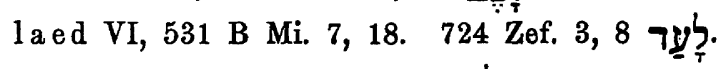

1aem VI, 77 E Mich. 7, 13 לְ. לִ.

la manasse V, 619 חל

lanu IV, 95 C Jes. 6, 8 דלנד

lebena IV, 336 D zu Jes. 24, 23 לבקָ⿻

le is IV, 404 D Jes. 30, 6 t? ?ִ.

lethech VI, $29 \mathrm{E}$ Hos. 3, 2 7.

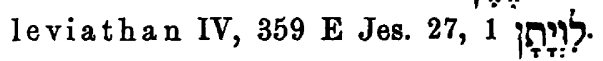

li T, 334 B Jes. 24, 16. VI, 898 E Sach. 12, 5 ??.

lilith IV, 445 B Jes. 34, 14 ליליה.

lola m V, 302 C Ez. 26, 21. VI, 704 B zu Zef. 2, 9 לִ לִ לִ

M.

Ma VI, 278 A zu Am. 4, 13 טֶָ.

ma ath III, 454 D Koh. 8, 12 חญ̣.

Zeitschrift f. d. alttest. Wiss. Jahrgang 4. 1884. 
mabsar IV, 890 A Jer. 6, 27 טִבְצ.

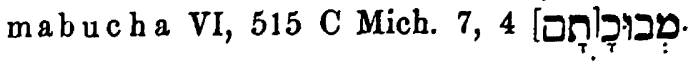

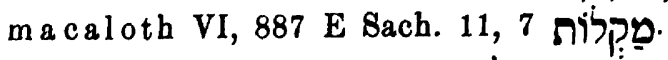

machal V, 595 D Ez. 47, 12 Dֵַָרָ.

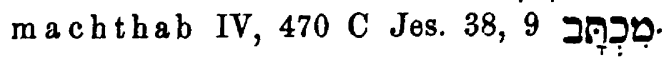

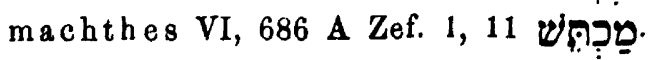

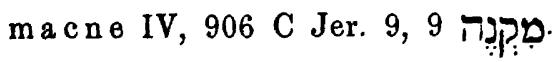

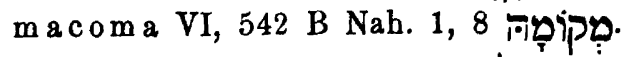

magdal V, 348 A Ez. 29, 10 מִגְרד

magras V, 609 B Ez. 48, 17 מגור

magur IV, 978 C Jer. 20, 3 טָגוֹר מער

mail IV, 737 C Jes. 61, 10 מִעִיל.

maim VI, $131 \mathrm{C}$ zu Hos. 11, 10 טַיפים.

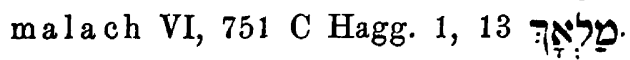

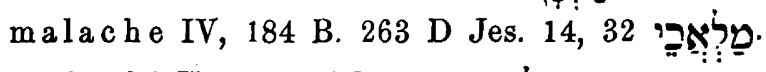

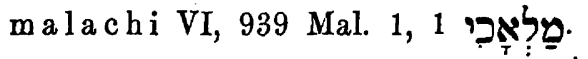

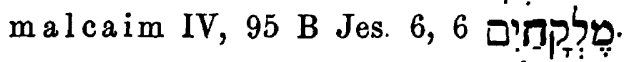

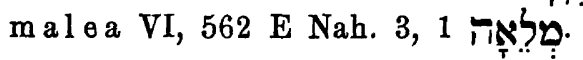

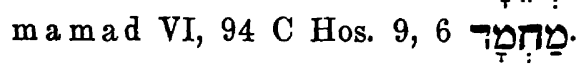

mamas a c VI, 703 D Zef. 2, 9 מִמְשׁ.

unamzer VI, 860 E Sach. 9, 6 Dַpְị.

manaa IV, 965 A Jer. 17, 26. V, 555 B Ez. 44, 29. 568 B ib. 45,

15. $573 \mathrm{~B}$ ib. 46, 5. $578 \mathrm{E}$ ib. 46, 14 מְִָּה

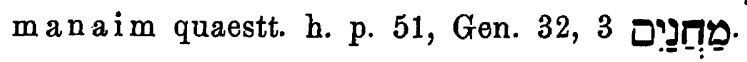

mane V, 655 D Dan. 5, 25 מְנִּא.

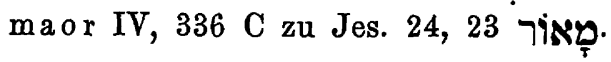

maoz IV, 402 A Jes. 30, 3 זע山.

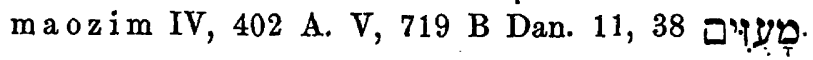

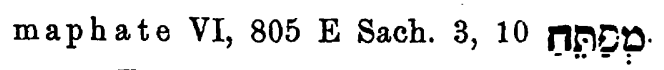

mara VI, 716 B Zef. 3, 1 עִ

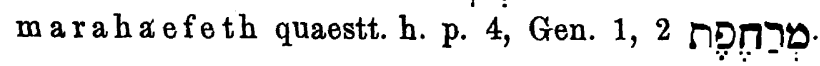

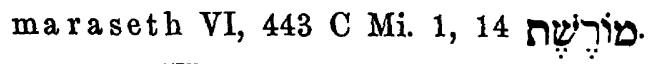

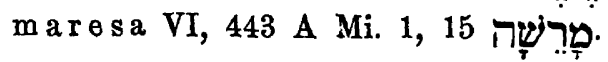

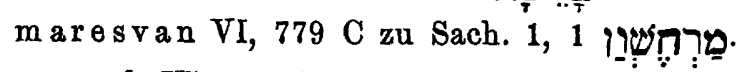

maroth VI, $442 \mathrm{C}$ Mi. 1, 12 פערוֹ.

marphe III, 470 B Koh. 10, 4 פרִ

masal IV, 247 C Jes. 14, 4 לִָד 


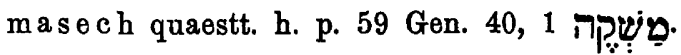

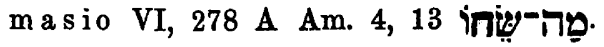

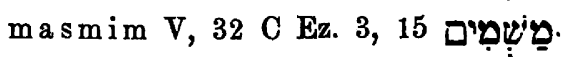

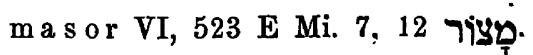

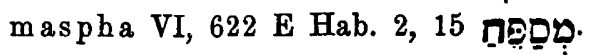

m ass a IV, 288 C Jes. 19, 1. 403 Jes. 30, 6. 1007 B Jer. 23, 38.

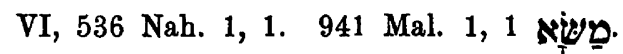

masur VI, 607 D Hab. 2, 1 רִִ̣.

mate V, 46 C Ez. 4, 16 טֵַ (constr.).

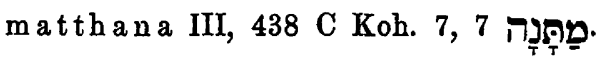

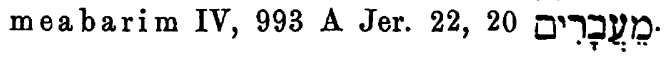

mebbeth VI, 226 D Am. 1, 5 מִביָית.

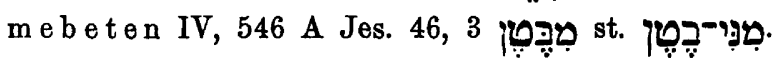

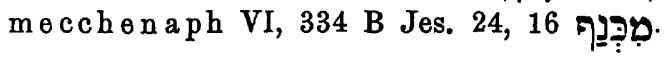

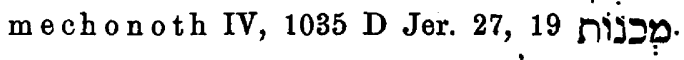

megella VI, 815 B Sach. 5, 1 מִ מִלְל

mej am VI, 131 C Hos. 11, 10 بִaים

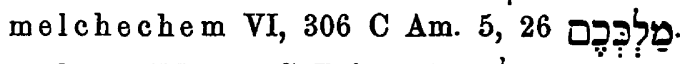

melcom VI, 680 C Zef. 1, 5 טַלְכָ.

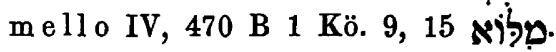

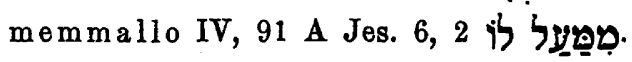

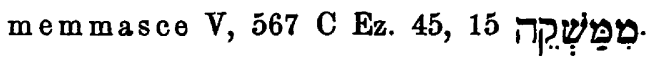

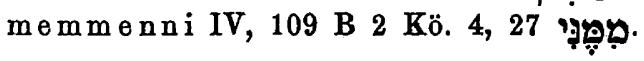

men IV, 43 D Jes. 2, 22 ب̣.

menecha quaestt. h. p. 54, Gen. 35, 8 מיקינקיקו.

menni IV, 546 A Jes. 46, 3 מִִ̣י

n IV

menno VI, 570 D Nah. 3, 8 מִ̣.

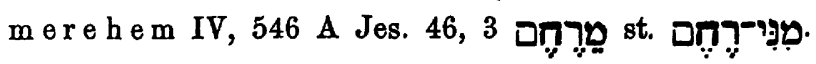

mereim IV, 13 D Jes. 1, 4 מִרְע

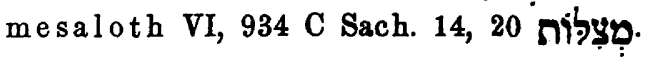

mesech quaestt. h. p. 25, Gen. 15, 2 p. מֶׁ.

mesphaa IV, 73 B Jes. 5, 7 पִשְ:

mesphat IV, 73 B Jes. 5, 7 טุุṭְ.

mesra IV, 134 A Jes. 9, 6 טִשְׁרִ

mesraim IV, 288 C Jes. 19, 1. 322 B ib. 23, 5. V, 342 A Ez. 29, 3.

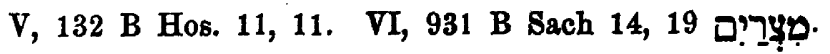


messa IV, 169 A Jes. 13, 1 טֵ.

messarim IV, 347 Jes. 26, 7 טיטיקרים

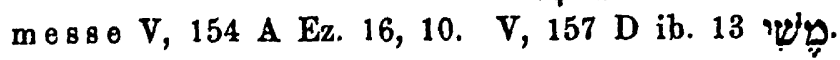

messio VI, 278 A zu Am. 4, 13 in מִ.

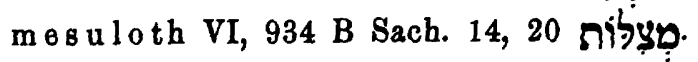

metheca IV, 357 C Jes. 26, 19 صמעת.

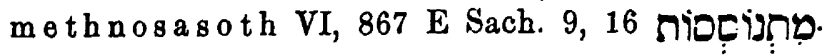

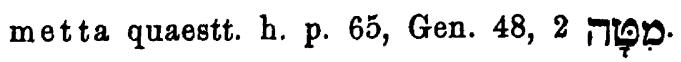

mezur VI, 58 D Hos. 5, 13 רiוn.

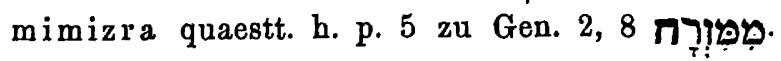

mnuatho IV, $161 \mathrm{C}$ Jer. 11, 10 innְ:

moces VI, 336 B zu Amos 8, 2 טip.

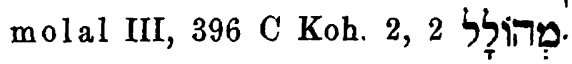

mopheph*) IV, 183 B Jes. 14, 29 ตפ๊

moria quaestt. h. p. 33, Gen. 22, 2 ט:

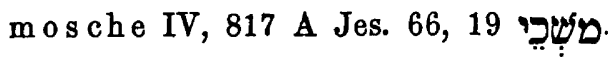

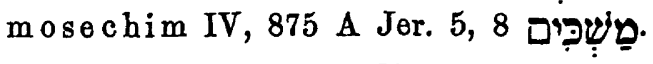

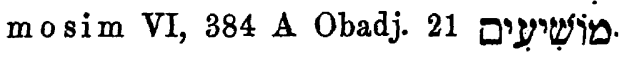

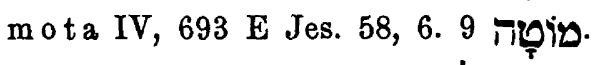

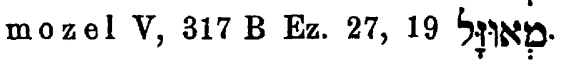

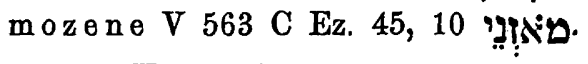

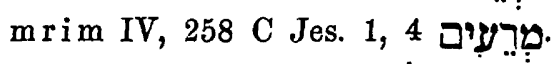

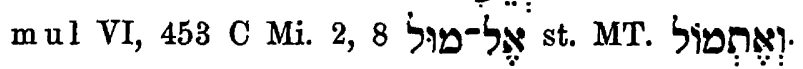

mutoth IV, 1031 C. D. 1038 C Jer. 28, 13 מטiv.

N.

N a al ma quaestt. h. p. 37, Hi. 28, 21 ș

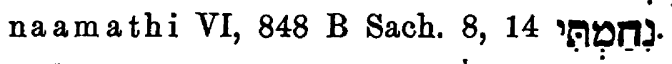

nabal IV, 427 E Jes. 32, 6 נָָד

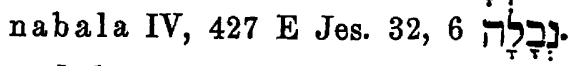

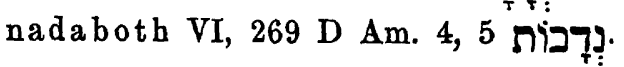

naoth VI, 183 B Jo. 1, 20 נִ נִאוֹ (constr.).

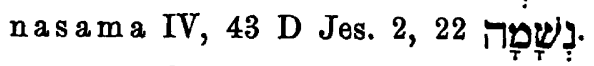

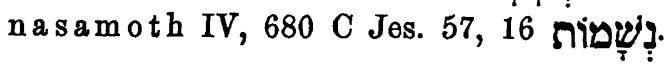

*) mophet bei Vallarsi ist offenbar Druckfehler. 


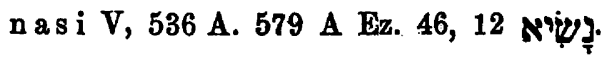

nasim IV, 57 B Jes. 3, 12 נִ שִׁים.

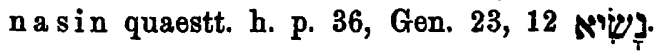

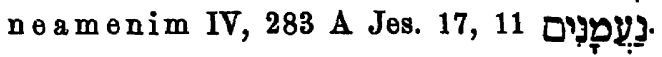

nebeim IV, 1036 D Jer. 28, 1 נְרִיאיָים

nebel IV, 932 B Jer. 13, 12 과ํ.

nebia IV, 1036 E Jer. 28, 1 נִבְִיאריא

nebim VI, 907 E Sach. 13, 2 נְבִיאִים

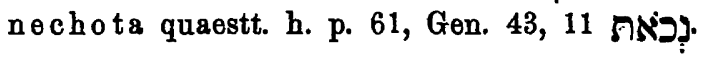

nechotha IV, 477 B Jes. 39, 2 נִכּזن.

neemanim 1V, 283 A zu Jes. 17, 11 פִ

negeb IV, 403 B Jes. 30, 6 נְְִּב.

nehel V, 591 B Ez. 47, 7 לू.

nehela IV, 282 B Jes. 17, 11. V, 613 D Ez. 48, 28 נְִִָ

nemer IV, 874 D Jer. 5, 6 נָָּ

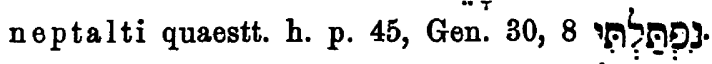

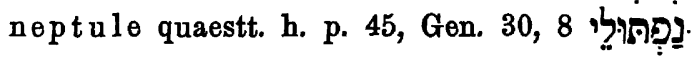

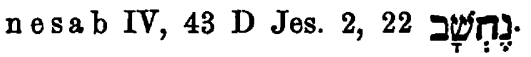

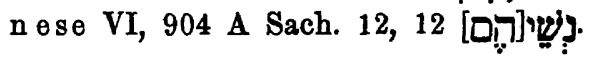

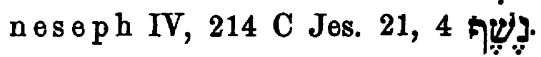

nesepha IV, 933 D zu Jer. 13, 16 ๆ

neser IV, 155 D Jes. 11, 1 7ูู

nesiche VI, 493 C Mi. 5, 4 נְפִיכָי

nesphe IV, 170 A Jes. 13, 2 3.

nesure IV, 565 A Jes. 49, 6 פְצורי (Qeri).

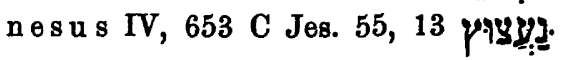

nethab IV, 179 B. 255 D Jes. 14, 19 נִתְע

$\mathrm{n} \in \mathrm{z} \in \mathrm{m}$ V, 155 C Ez. 16, 12 נִּנְ.

nifilim quaestt. h. p. 12, Gen. 6, 4 נְפִלילים.

nocedim VI, 222 B. C Am. 1, 1 נ:ק్ נקירים.

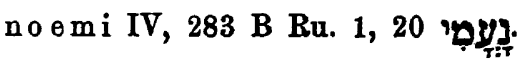

noges VI, 872 E Sach. 10, 4 נing.

nugae VI, 730 B Zef. 3, 18 ,

0.

O i IV, 334 B Jes. 24, 16. 388 B Jes. 29, 1 יאוא.

oiim IV, 245 C Jes. 13, 21 arriks. 
omer IV, 75 A Jes. 5, 10. VI, 29 E Hos. 3, 2 רֶ.

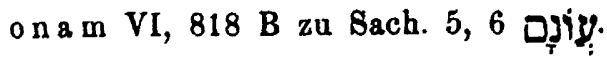

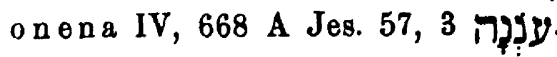

on $\theta \mathrm{ph}$ IV, 428 A Jes. 32, 6 ๆ

ophaz IV, 912 D Jer. 10, 9. V, 697 E Dan. 10, 5 איפד.

ophel IV, 430 A Jes. 32, 14. VI, 481 B Mi. 4, 8 עפูป.

ophir IV, 172 E Jes. 13, 12 אוֹפקיר.

or IV, 425 D Jes. 31, 9 אור.

orbim IV, 188 A zu Jes. 15, 7 עוֹרִבְים.

oreb IV, 150 C Jes. 10, 26. VI, 749 A Agg. 1, 11 עוֹרברביר.

orobba VI, 145 E Hos. 13, 3 אִרְּר

oroth IV, 357 A Jes. 26, 19 תiา.

P.

Phacud V, 266 C Ez. 23, 23 פִקוֹר.

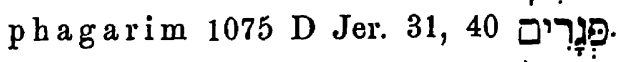

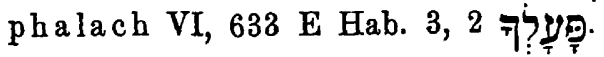

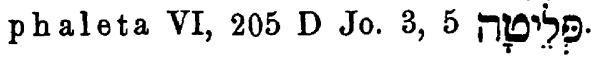

phanag V, 314 E Ez. 27, 17 פون.

phanau IV, 91 B Jes. 6, 2 פִָד.

phar V, 531 D Ez. 43, 23 פַּ.

pharasim IV, 383 B Jes. 28, 21 פִּרִ

phares V, 655 D Dan. 5, 25 פִִּ

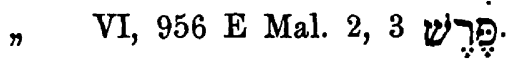

pharim VI, 158 A Hos. 14, 3 פֶָרים

pharis V, 212 D Ez. 18, 10 פֶָר

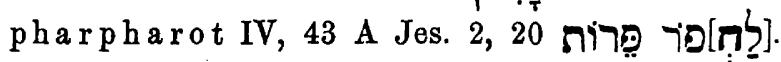

phase V, 293 B zu Ez. 25, 15. IV, 423 E Jer. 31, 5. VI, 791 D zu

Sach. 1, 1 פฺָ̣.

phatuel V, 167 A Jo. 1, 1 לְִ̣.

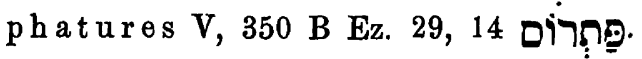

phaz IV, 172 E 241 E Jes. 13, 12 国.

phele IV, 133 A Jes. 9, 5 פְֶ?.

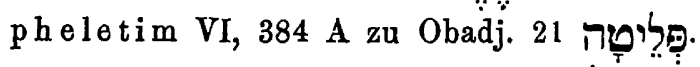

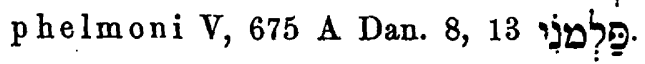

pherec VI, 562 E Nah. 3, 1 Pְִ̣. 
pheres VI, 698 E Jes. 58, 12 פִּר

pheri VI, 158 A zu Hos. 14, 3 פִּר

phethee VI, 805 E Sach. 3, 10 פִחקִ

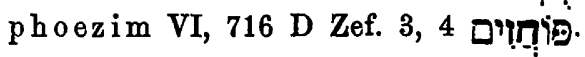

photha VI, 76 B Mi. 7, 11 פחוֹ.

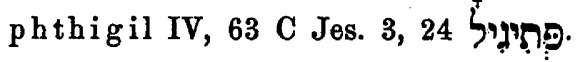

phura IV, 154 E Jes. 10, 33 פִפארי

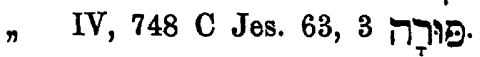

phut V, 309 C Ez. 27, 10 פוּ.

R.

Raath III, 452 B Koh. 8, 6. VI, 850 D Sach. 8, 17 רע עִ

racadu VI, 903 B zu Sach. 12, 10 s. o. dacaru.

rachil V, 254 D Ez. 22, 9 רִִִיל

rachus quaestt. h. p. 23, Gen. 14, 16 רִּ̣:

rad VI, 133 B Hos. 12, 1 7רุ.

ra h a quaestt. b. p. 52, Gen. 32, 29 רָָ רָ.

raim IV, 663 A zu Jes. 56, 11 רְצִים

r a me IV, 471 B zu Jes. 38, 10 s. o. dame.

ramoth V, 314 C Ez. 27, 16 תiמֻז.

raphaim IV, 353 B. 357 A Jes. 26, 19. VI, 289 A zu Am: 5, 8

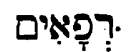

rath ath VI, 144 B Hos. 13, 1 ก: רְ:-

rau VI, 593 E Hab. 1, 5 in?:

re VI, 29 A Hos. 3, 1 quaestt h. p. 58 Gen. 38, 12 עา.

reah IV, 379 B zu Jes. 28, 9 רעז

recob VI, $57 \mathrm{C}$ Hos. 5, 12 דרָד

reeb IV, 406 A Jes. 30, 7 ברָำ.

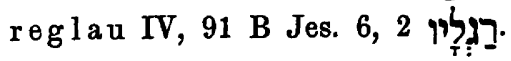

rehem VI, 235 E Am. 1, 11 רֶ.

reim IV, 856 E Jer. 3, 1. 882 C zu Jer. 6, 3 רעים

remes VI, 605 C Hab. 1, 14 ๒ุ.

resa IV, 349 C Jes. 26, 10 עยฺุ

resen VI, 934 D zu Sach. 14, 20 רק:

reseph VI, 641 B Hab. 3, 5 רִ

ro quaestt. h. p. 58 zu Gen. 38, 12 ค่า 


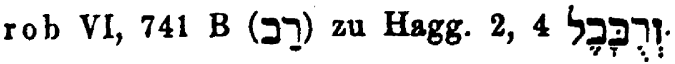

roi IV, 531 B Jes. 44, 28 רעי

roim IV, 856 E zu Jes. 3, 1. 663 A Jes. 56, 11. 882 C Jer. 6, 3 .רעטים

rooth III, 393 D Koh. 1, 14 רעו

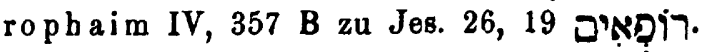

ros V, 445 D Ez. 38, 3 แหา.

rou IV, 120 D Jes. 8,9 רעו 9.

ruah IV, 485 C Jer. 10, 13. VI, 277 E Am. 4, 13 רוּ.

ruha III, 435 B Koh. 6, 9 กרוּ.

rubi V, 458 E Ez. 39, 29 רוּ.

S.

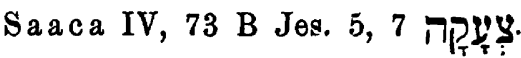

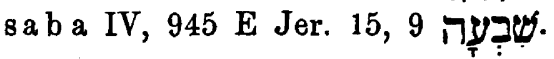

sabaa IV, 786 C Jes. 65, 15 שִׁבוּעִ

sababim VI, 83 E. 84 A Hos. 8, 6 ששׁכָרבים

sabai V, 720 E Dan. 11, צִבְי 41.

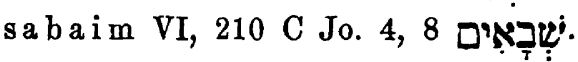

sab a o th IV, 527 B Jes. 44, 6 צִבָאטוֹ

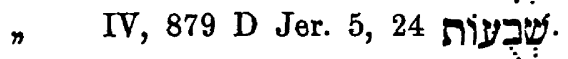

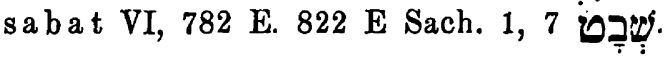

sa be c h quaestt. h. p. 34, Gen. 22, 13 סִ:

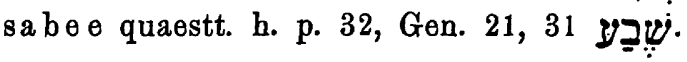

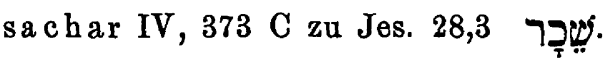

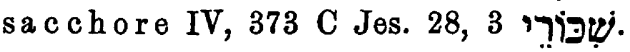

sadaca IV, 73 B Jes. 5, 7 צִרָקָר

sadai IV, 808 D Ps. 80, 14 שָָׁרָר

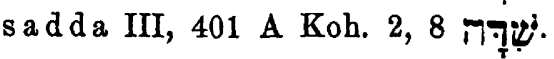

saddai V, 19 D Ez. 1, 24

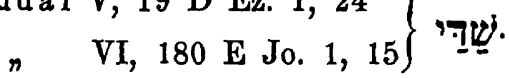

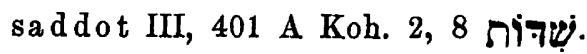

sade V, 241 D Ez. 21, 2 שֶֶָׁ.

\ VI 827 C zu Sach. 6, 12 צִרָ

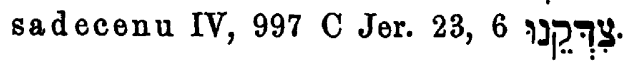

s ad oc V, 531 D Ez. 43, 19 piา צ̦. 


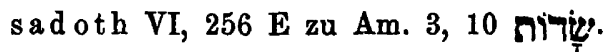

s adud IV, 871 D Jer. 4, 30 797ש.

saith IV, 71 E Jes. 5, 6. 363 A. Jes. 27, 4 שִ.

sala VI, 187 A Jo. 2, 8 שִ.

salami in quaestt. h. p. 54, Gen. 34, 21 שֶלִמִים.

sal is IV, $487 \mathrm{C}$ Jes. 40, 12 שִ של

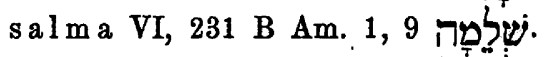

salos VI, 416 C Jon. 3, 4 שָ.

s am IV, 378 A Jes. 28, 10. VI, 638 B Hab. 3, 4 שָ.

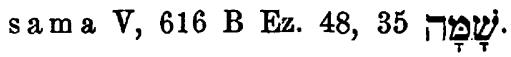

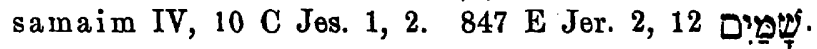

sa mir IV, 363 A Jes. 27, 4. 957 A Jer. 17, 1. VI, 836 B Sach. 7,

12 שִִָׁׁיר

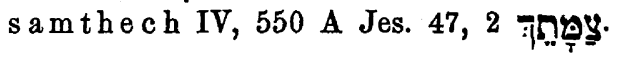

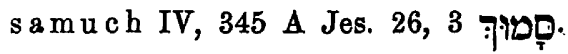

sane V, 141 D Ez. 15, 4 שִני (Jahre).

sanif VI, 801 A Sach. 3, 5 ๆ צִ

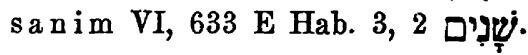

sannoth VI, 266 A Am. 4, 2 月ijgy.

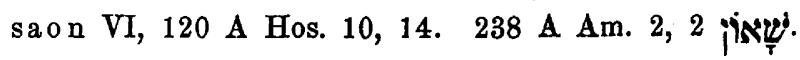

sa pharad VI, 383 C Obadj. 20 רִּุ.

saphir VI, 441 E Mi. 1, 11 שฺִָׁ.

saphon IV, 1019 A Jer. 25, 26 joy̦.

$\left.\begin{array}{l}\text { saphphon } \\ \text { saphphonim }\end{array}\right\}$ IV, 903 A Jer. 8, 17 צִפעצִים.

s a r IV, 148 E Jes. 10, 21 שุ.

ก VI, $258 \mathrm{C} \mathrm{Am.} \mathrm{3,} 11$ רצ.

saraf IV, 404 D Jes. 30, 6 שָרָר

saraph IV, 183 B Jes. 14, 29 ๆ

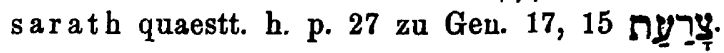

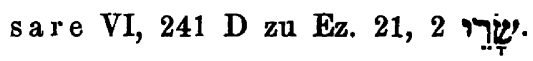

sariagim quaestt. h. p. 59, Gen. 40, 10 שֶרִירגים

sarid VI, 379 B Obadj. 18 שָׁריד

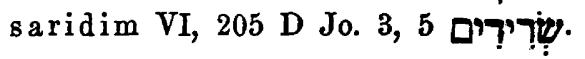

sarim VI, $140 \mathrm{E}$ zu Hos. 12, 12 שָׁרִים

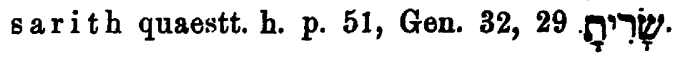




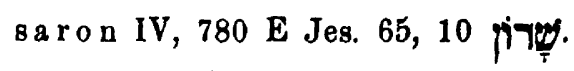

sarphod IV, 653 D Jes. 55, 13 סרק

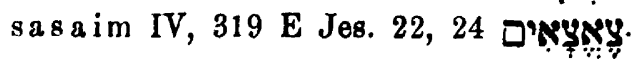

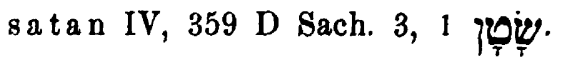

sattim VI, 215 E Jo. 4, 18 שִׁיִ.

sau IV, 378 A Jes. 28,10 צִ.

seced [III, 491 A Koh. 12, 5] IV, 840 A Jer. 1, 11 T2

s ecel quaestt. h. p. 36, Gen. 23, 15 שֶׁק.

secuse V, 225 E Ez. 20, 7 שִקוּיצי

sedec IV, 25 A Jes. 1, 21 Pִֶֶ.

sedim quaestt. h. p. 23, Gen. 14, 3. 8.10 שִדְדים

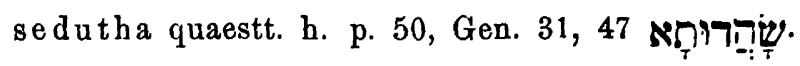

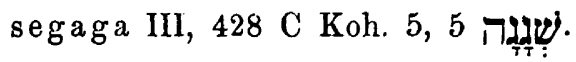

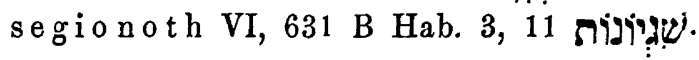

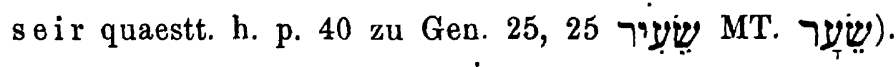

sel IV, $197 \mathrm{D}$ zu Jes. 18, 1 צ̧.

sela VI, 637 E Hab. 3, 3. 657 D ib. v. סֶלדה 13.

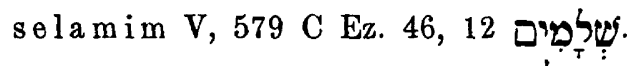

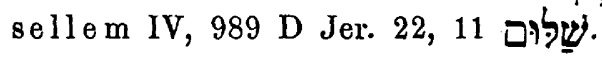

selsel IV, 197 D Jes. 18, 1 צִ צִלְצִ (constr.).

selua quaestt. h. p. 70, Gen. 49, 21 שִּלְחָ

sema VI, 827 C Sach. 6, 12 צְִִָ.

semanim IV, 371 E Jes. 28, 1 שִׁמָנִים

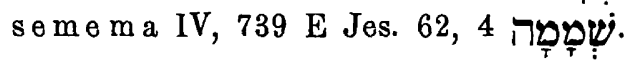

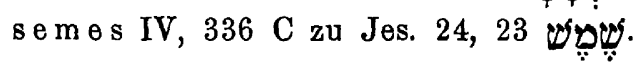

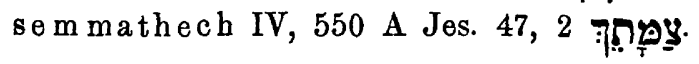

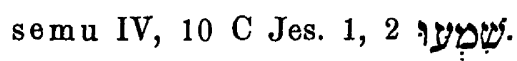

sen e V, 141 D Ez. 15, 4 (zwei).

seorim VI, 29 E Hos. 3, 2 שֶוֹערים

seph V, 470 B Ez. 40, 6 Пָ.

sephar psalter. iuxta Hebr. Hieron. ed. Lag. 1874 p. 2 סֵפְר

sephela IV, 964 E Jer. 17, 26. 1092 D Jer. 32, 44 שִשְְָׁלְר

sephat IV, 319 E Jes. 22, 24 צִפִיעוֹ.

sephphira V, 65 C Ez. 7, 10 צִפירָר

seraf IV, $94 \mathrm{C}$ zu Jes. 6, 6 ๆ שָדָ

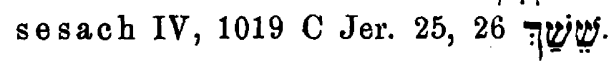


setta IV, 502 B Jes. 41, 19 שִ

settim VI, 502 C Mi. 6, 5 שישים.

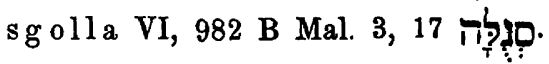

sia VI, 278 A Am. 4, 13 iñ

sicera IV, 76 B Jes. 5, 11 שֶכָר

sig V, 256 A Ez. 22, 18 Qִ Qeri.

sigim IV, 25 C Jes. 1, 22 مְנגים.

siim IV, 174 E. 245 B Jes. 13, 21. 444 D Jes. 34, 14. V, 716 C

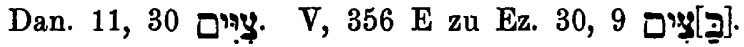

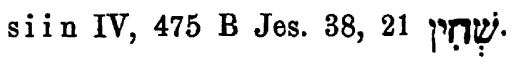

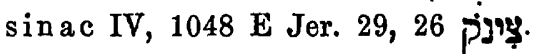

sinim IV, 568 A Jes. 49, 12 סִינִים.

sinthoroth VI, 813 B Sach. 4, 12 תבְִּ

sionim IV, 1068 C Jer. 31, 21 פִ̣:

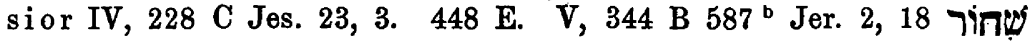
sir VI, 366 E Obadj. 1 צִיר.

sirim IV, 245 D Jes. 13, 21 שִעִִירים

sis IV, 473 A zu Jes. 38, 14 D.

soced III, 491 A Koh. 12, 5. IV, 840 A Jer. 1, 12. 874 D Jer. 5, 6

ש.קי

socen IV, 224 E Jes. 22, 15 סذٍّן.

sochoth VI, 306 D Am. 5, 26 תבס.

socoth quaestt. h. p. 53, Gen. 33, 17 กوפฺ̣.

sod IV, 189 D Jes. 16, 4. VI, 77 E Mi. 7, 13 שن.

soeph III, 387 D Koh. 1, 5 ๆsile.

sohel VI, 59 D Hos. 5, 14 לש̃.

s oor V, 316 D Ez. 27, 18 ר్צ̦.

sophar IV, 684 D Jes. 58, 1. VI, 54 A Hos. 5, 8. 81 C Hos. 8, 1.

238 A Am. 2, 2 רị.

sor IV, 320 E Jes. 23, 1. V, 294 D Ez. 26, 2. 299 C ib. 26, 15. VI, 100 A Hos. 9, 13. $258 \mathrm{C}$ zu Am. 3, 11 үy.

sorec IV, 69 B Jes. 5, 2. 850 A Jer. 2, 21 שפר

s ot IV, 380 B Jes. 28, 15. 18 טif.

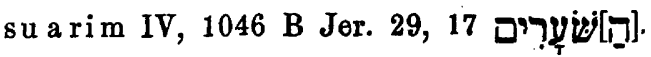

sud VI, 100 A zu Hos. 9, 13 7.y.

sue V, 266 C Ez. 23, 23 vִié. 
s u r IV, 150 C Jes. 10, 26. 346 A Jes. 26, 4. VI, 100 A zu Hos. 9,

13. $258 \mathrm{D}$ zu Am. 3, 11 רצs.

8 urim VI, 140 E Hos. 12, 12 שים

sus IV, 473 A Jes. 38, 14 Dוּ.

T.

Tallim psalter. ed. Lag. p. 2, nach spätbebr. Abkürzung פְתִ st.

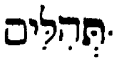

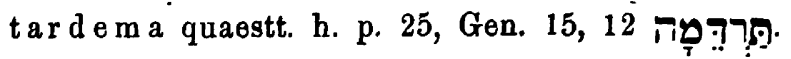

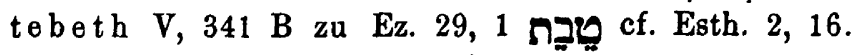

tephphol V, 82 A Ez. 8, 1 לต̣.

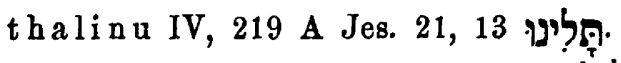

thalule IV, 801 E Jes. 66, 4 [ת]

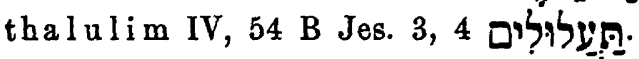

thamar V, 475 E zu Ez. 40, 16, quaestt. h. p. 23, Gen. 14, 7 רฺฺָָ.

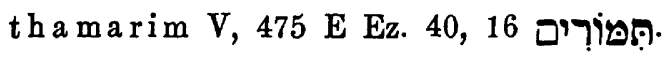

thamim V, 578 E Ez. 46, 13 מִִ̣̣.

thamoddu V, $600 \mathrm{E} \mathrm{Ez.} \mathrm{47,} 18$ 詡

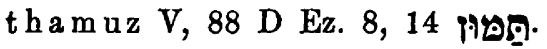

thannim IV, 245 E Jes. $13,22.521$ A ib. 43, 20. 916 B Jer. 10, 22

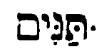

thannin IV, 361 E Jes. 27, 1 ตּู

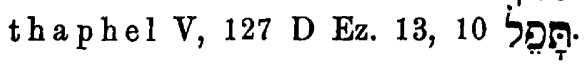

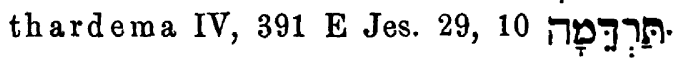

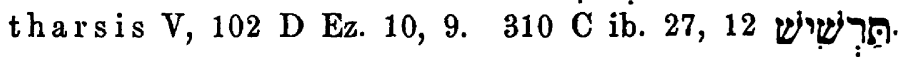

thas V, 152 D Ez. 16, 10 ש. פู.

thav IV, 713 A Ez. 9, 4 พจุ.

thebel IV, $172 \mathrm{C}$ Jes. $13,11.254 \mathrm{E}$ ib. 14, 17. $356 \mathrm{~A}$ ib. 26,18

רִּרֶ.

thecel V, 655 D Dan. 5, 25 קִִּ̣

thee V, 480 C. 483 Ez. 40, 21 ịฺุ.

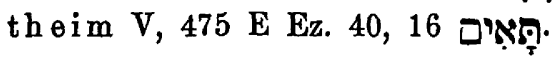

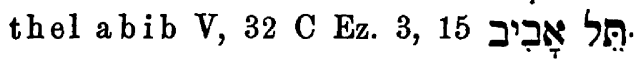

theman VI, 636 D Ab. 3, 3 ר్קיר

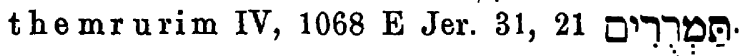

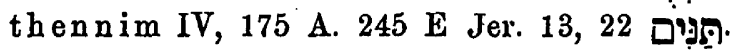




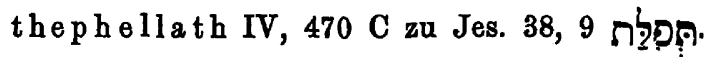

therafim quaestt. h. p. 50, Gen. 31, 19 קרקִ

therua VI, 238 A Am. 2, 2 הְִּּ

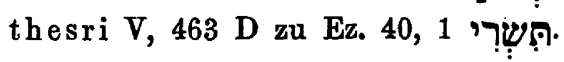

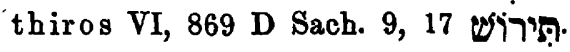

tho IV, $597 \mathrm{E}$ Jes. 51, 20 Niร.

thoda IV, 965 B Jer. 17, 26. 779 D zu Jes. 65, 8. 1057 B Jer. 30,

19. VI, 269 D Am. 4, 5 ה דุi

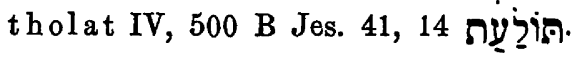

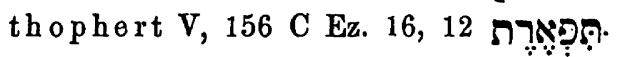

thophet IV, 975 A Jer. 19, 6 กอุ.

to bim VI, 851 C Sach. 8, 19 טִביن.

tophet IV, 897 C Jer. 7, 31 กจูร.

turoth V, 582 E Ez. 46, 23 טירוֹת.

U.

Ubal V, 673 A Dan. 8, 3 אִבְל

ul V, 475 C zu Ez. 40, 16 אָיָּר

ulam V, 483 A zu Ez. 40, 24. 25. VI, 193 C Jo. 2, 17, quaestt. h.

p. 44 אוּלְ.

u lo IV, 107 C Jes. 7, 12. VI, 848 B Sach. 8, 14. 932 D Sach. 14, 17 וְלְ.

ur IV, 425 D Jes. 31, 9, quaestt. h. p. 19. 25, Gen. 11, 28 אוּ.

uraithi V, 496 D Ez. 41, 8 וְרִ

urob V, 492 E Ez. 40, 49 כו̣

V.

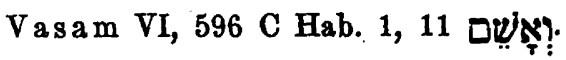

Z.

Zachar IV, 353 B Jes. 26, 14 זֶכ

zanunim VI, 3 E Hos. 1, 2 זְנוּנִיפרים

zara V, 372 B Ez. 31, 17 iעา จon Hieron. auch als möglicher

Weise = iทา !ִ bezeichnet.

ze ba V, 582 E zu Ez. 46, 20 ก)

zemma V, 170 A Ez. 16, 27. 274 D ib. 24, 13 กตุ?!: 
zemroth IV, 334 E Jes. 24, 16 חפוֹ:

zer IV, 378 A Jes. 28, 10 נעִיר?

zera IV, 258 C Jes. 1, 4 עד?.

ziz IV, 808 C. D Jes. 66, 11 ఛ̣.

zo VI, 741 B zu Hagg. 1, 1 \%.

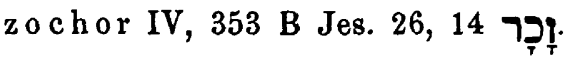

zor V, 82 A Ez. 8, 2 7구.

Versuchen wir nunmehr aus der vorstehenden Sammlung einige Schlüsse zu ziehen oder, wo so viel Sicherheit sich nicht erreichen läIst, einige Vermuthungen an dieselbe zu knüpfen. - Die Unsicherheit des Hieronymianischen Textes kann uns in solchen Fällen nicht stören, wo ganze Reihen von analogen Schreibungen vorliegen. Nur bei vereinzelten Transscriptionen wird Vorsicht geboten sein. - Wir betrachten :

\section{Consonanten.}

\section{a) Mutae.}

\section{P - L a u t e.}

$\S 1$. ב wird durch b wiedergegeben. Nach Cors sen, über Aussprache, Vokalismus und Betonung der lateinischen Sprache, 2. Aufl., 1868. 1870, Bd. 1, S. 134, hat sich das lateinische b seit Anfang des 4. Jahrhunderts p. Chr. erweicht und ist dem Laute des $\mathrm{v}=\beta$ ähnlich geworden $*$ ). Nach Analogie der hier gleich zu besprechenden Behandlung der $\square$ bei Hieronymus wird auch für ב stets eine weiche Aussprache anzunehmen sein. So bei benadad

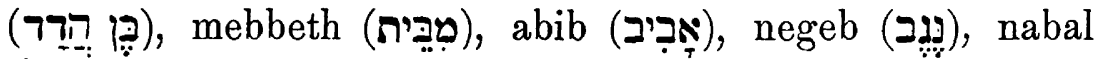

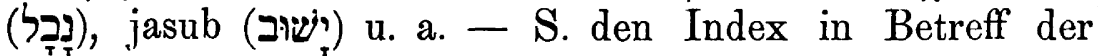
Belege hier und in allen folgenden Fällen. Am Silben-

*) Ueber die durchgängig aspirirte Aussprache des $\beta$ s. Bla fs, über die Aussprache des Altgriechischen 1869, S. 25. 
schlusse ward wohl kaum ein Unterschied zwischen $ב$ und $\square$ gehört. Auch die LXX schwanken hier in der Um-

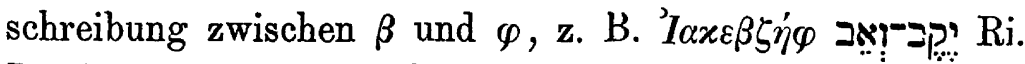
7, 25, vgl. auch Frankel, Vorstudien zu der Septuaginta 1841, S. 108; über die weiche Aussprache des $ב$ bei Palästinern s. auch S. 102.

$D$ ist bei Hieron. nur in einem einzigen Falle durch p wiedergegeben *), welchen er seiner Merkwürdigkeit wegen besonders hervorhebt. Es ist dies das Wort in Dan. 11, 45, das er Apedno umschreibt mit der Bemerkung : in isto tantum loco apud Hebraeos scribatur quidem Phe sed legatur Pe (opp. ed. Vallarsi V, 724 C.), worin Hieron. mit Saadja zu Sefer jezira übereinstimmt, wie Graetz, jüd. Mtsschr. 1881, S. 511-514 nachweist. In dièsem Falle ist also der harte labiale Verschlufslaut gesprochen, als welcher $\mathrm{p}$ im Lateinischen stets lautete (s. Corssen I, 113).

Die sonst ausnahmslose Aussprache des D war also die weiche, welche auch die LXX fast stets haben, vgl.

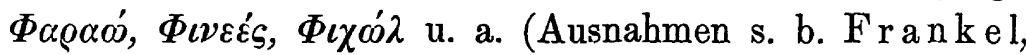
S. 112). Hieron. sagt ed. V all. a. a. O. notandum quod $\mathrm{Pe}$ literam Hebraeus sermo non habeat sed pro ea utatur Phe cujus vim Graecum $\varphi$ sonat, vgl. auch IV, 35 A. - Er giebt es daher durch ph wieder, wie dies in der älteren Schreibung bei griechischen Fremdworten mit $\varphi$ geschah, oder mit $f$, wie in der späteren lateinischen Volkssprache $\varphi$ gesprochen wurde (Corssen I, 173). Letztere Orthographie ist in quaestiones hebraicae in libro Geneseos ed. de Lagarde 1868 : z. B. fara פֶּר p. 36, therafim p. 50, ebenso im psalterium iuxta Hebraeos Hieronymi 1874, p. 113 Finees. Durchweg ist im Anlaut

*) Abgesehen von Eigennamen wie z. B. Zapfanethfane in quaestt. in Genes. ed. Lag. p. 61, 1 , Neptali ib. p. 45, 22, damit zusammenbängend neptule u. neptalti ib. 45, 25. 
F im liber interpretationis hebraicorum nominum und im liber de situ et nominibus locorum hebraicorum s. Lagarde, onomastica sacra $1870 \mathrm{I}$, p. $6,11-22$, p. 13, 6-12, p. 18, $15-22$, p. $22,16.17$, p. $27,21.22$, p. $32,17-19$, p. 35 , 22. 23, p. 45, 22-26 u. a. Meist ist auch im In- oder Auslaute die Schreibung f, selten ph, wie aleph p. 9, 16, respha p. 39, 22.

Dagegen bei Vallarsi findet sich die Schreibung mit f selten IV, $94 \mathrm{C}, 404 \mathrm{D}, \mathrm{VI}, 801 \mathrm{~A}$, sonst in der weit überwiegenden Mehrzahl der Fälle steht ph. Es bedarf dieser Punkt demnach noch einer textkritischen Aufklärung. - Im Uebrigen s. den Index.

Bei der Verdoppelung erscheint zweimaliges $p h$ in :

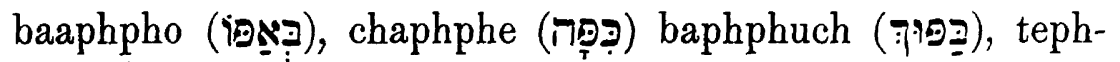

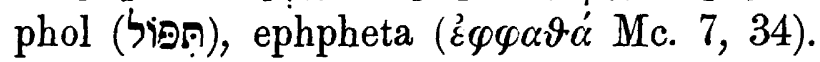

Auch beim schnelleren Zusammensprechen zweier Worte so: (cf. Dagesch forte conjunctivum) aphpho =

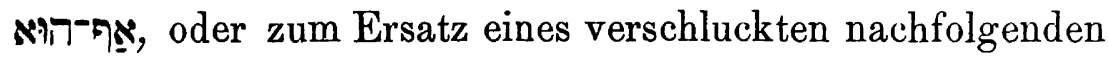
Hauchlauts z. B. saphphonim = צִפְענִים

\section{$\mathrm{K}$ - L a u t e.}

a wird wird wie g gesprochen, s. den Index. - Ueber die Aussprache des lat. g s. Corssen I, 96.

$\checkmark$ kommt wie fast durchweg in der weichen Aussprache vor, wie denn Hieron. bei V all. V, $449 \mathrm{C}$ den Buchstaben geradezu chi nennt. Das entspricht der jüdischen Bezeichnung in der Mishna, welche das 2 in Menachot 6, 3 dem כי יונית, dem griechischen $\chi$, gleich setzt, sowie der Aussprache bei den LXX, welche $\supset$ bei Weitem in den

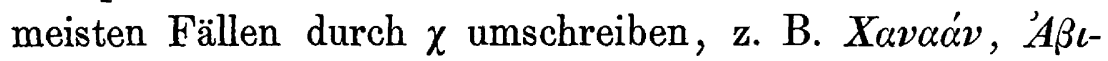
$\mu \varepsilon \lambda \varepsilon^{\prime} \chi, X \varepsilon \varrho \alpha^{\prime} \beta, X_{\alpha}^{\prime} \lambda \varepsilon \beta$ u. a. So bei Hieron. chi $=$ 'כ, chen

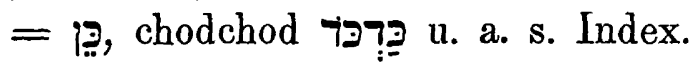

Bei der Verdoppelung erscheint einfaches ch. So bei

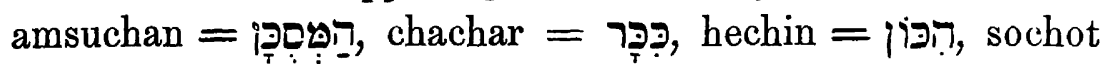

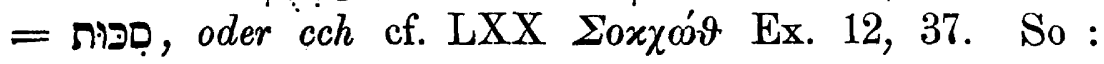




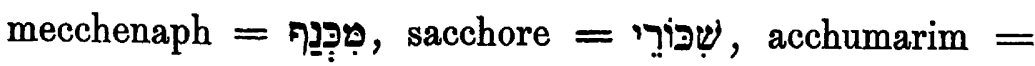

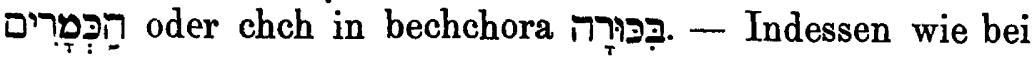
den LXX für $\supset$ einzelne Schreibungen mit $x$ vorkommen (vgl. Frankel S. 111), so bei Hieron. mit $c^{*}$ ). So in cas-

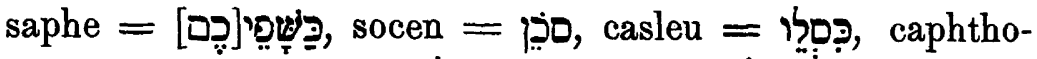

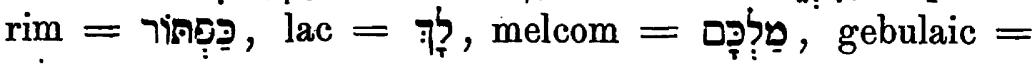

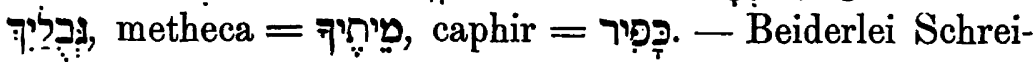

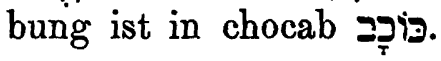

P giebt Hieron. durchweg durch $c$ wieder, wie LXX meist durch $x$ (Ausnahmen s. b. Frankel S. 112). Hieronymus sagt V, $449 \mathrm{C}$,ce quae hebraice dicitur coph." Hierbei ist zu beachten, dafs das lateinische $a$ auch vor e und i zeitweise wie $x$ gelautet hat vgl. Corssen I, 48; Schuchardt I, 162. So schreibt Hieron.

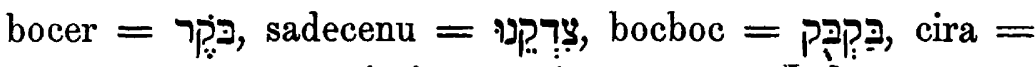

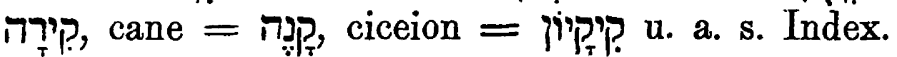

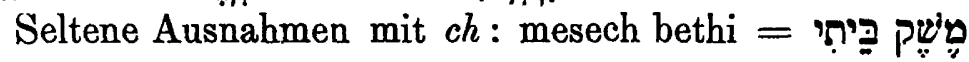

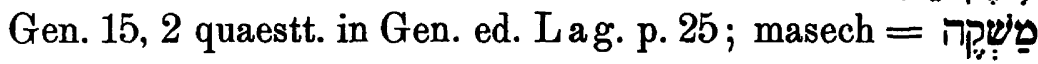
ib. p. 59 .

\section{T - L a u t e.}

§.3. 7 ist $=$ d. Dies im Wesentlichen wie deutsches $d$ gesprochen s. Corssen I, 219. - ת giebt Hieron. stehend durch th wieder, auf welche Weise auch die griechischen Fremdworte mit $\vartheta$ umschrieben wurden, da den Lateinern eine aspirirte Aussprache der tenues überhaupt fremd war : s. Corssen I, 167.

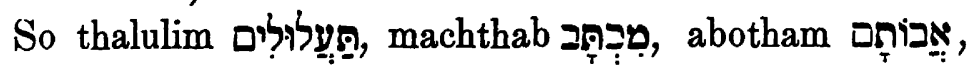
oroth Sinis u. a. s. den Index. - Ein Únterschied zwischen ת und $\Omega$ wird also überhaupt nicht gemacht.

*) $\mathrm{Zu}$ beachten ist indessen, dafs im Spätlateinischen c oft wie ch ausgesprochen wurde: 8. H. Schuchardt, der Vocalismus des Vulgärlateins 1866-1868, Bd. 1, 8. 73.

Zeitschrift f. d. alttest. Wiss. Jahrgang 4. 1884. 
Die Beispiele von Schreibungen mit $t$ sind daher, falls nicht überhaupt handschriftliche Fehler vorliegen, für zufällige anzusehen, zumal bisweilen daneben die Schreibung th vorkommt.

So findet sich für תסูต thophet und tophet, für nechotha neben nechota = נְכבזאת , für thardema und tardema. - Sonst finden sich tephphol = לiตn, aste $=$

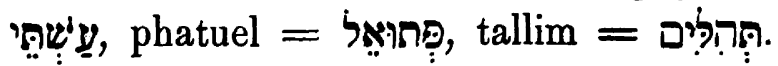

$\vartheta$ ist $=$ t. Letzteres ist bei den Lateinern stets als feste scharfe tenuis gesprochen : s. Corssen I, 174.

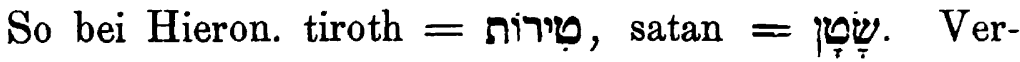

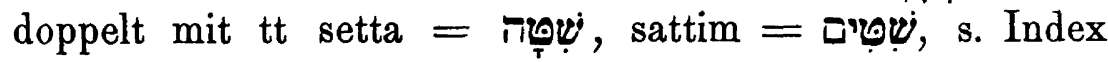
und die Beispiele bei Lag. on. s. I, 11, 14. 30, 20-24. 33, 26. 27. $43,20-23.49,3.51,3$ u. a.

\section{b) Zischlaute.}

§ 4. Hieronymus unterscheidet 3 S-Laute. Er sagt : de nom. hebr. (b. Lag. on. s. I, 10, 1-11) apud Hebraeos tres s sunt litterae. Una quae dicitur samech et simpliciter legitur quasi per s nostram literam describatur, alia sin, in qua stridor quidam non nostri sermonis interstrepit (cf. quaestt. h. p. 43,4 stridulum sin], tertia sade, quam aures nostri penitus reformidant. Daraus geht hervor, dals 1) Sain von ihm nicht mit zu den S-Lauten gerechnet wird und dafs er 2) keinen Unterschied zwischen $\boldsymbol{E}$ und $\boldsymbol{*}$ macht*). Er umschreibt daher die Laute $\boldsymbol{w}, \boldsymbol{v}, \mathbf{\square}, \mathbf{s}$ alle mit $\mathrm{s}$, weil das Lateinische kein anderes Lautzeichen besitzt, kennt aber das $\square$ als gelindes $s$, das $\boldsymbol{w}, \boldsymbol{w}$ als

*) $\mathrm{Ob}$ dies quaestt. in Gen. ed. L a g. 6, 10-12. 43, 1-7 geschehe, ist unsicher. - Ganz deutlich aber spricht gegen eine Unterscheidung von $2 y$ und $\uplus$ die Stelle VI, 278 A, wo Hier. sagt, wenn Messio= Christum suum sei, so werde es Mem Sin Jod Heth Vau geschrieben

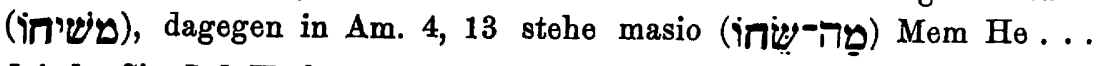
deinde Sin Jod Heth, quod legimus sia. O autem quod scribitur per solam literam Vau ... „ejus ${ }^{\mu}$ significat... 
schärferes und das $\mathbf{y}$ als schärfstes $\mathrm{s}$, welches dem $\mathrm{z}$ nahe steht, wie er IV, $155 \mathrm{E}$ über dasselbe sagt : cujus proprietatem et sonum inter $\mathrm{z}$ et $\mathrm{s}$ latinus sermo non exprimit; est enim stridulus et strictis dentibus vix linguae impressione profertur. An einer anderen Stelle beklagt er sich, dafs diese abscheuliche Zischelei sich selbst in seine lateinische Aussprache hineindränge praef. l. III in Galat. p. 486. (Z ö c kler, Hieronymus 1865, S. 324 bezieht dies irrthümlich auf den Stil. Der kann aber nicht durch Zischlaute verderbt werden).

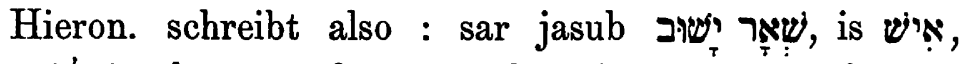

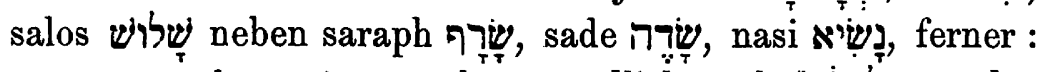

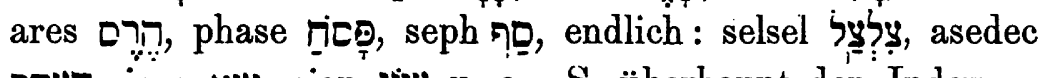

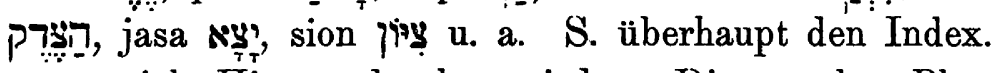

I giebt Hieron. durch $\mathrm{z}$ wieder. Dies ward zu Plautus Zeit ähnlich wie sz gesprochen, galt also damals als schärferer Zischlaut (Corssen I, 295), später aber scheint es weicher etwa wie griech. $\zeta=\mathrm{ds}$ gelautet zu haben (vgl. über dieses Blafs S. 26. 27), durch welches die LXX stehend das \& wiedergeben (s. Frankel S. 109). Die spätere weichere Aussprache des z zeigt zabulụs = diabolus, s. Schuchardt I, 67. 74.

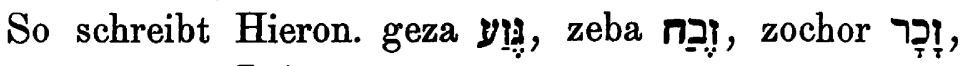
araz

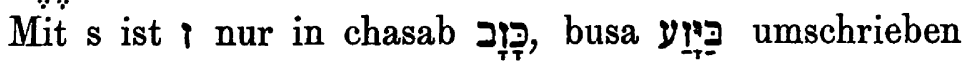
s. Index.

\section{c) Hauchlaute (Kehlhauche).}

$\S 5$. In der Behandlung der Hauche herrscht viel Verwirrung. Wir werden darüber milder denken, wenn wir erwägen, dafs bereits zu Christi Zeit die Galiläer in ihrer Aussprache incorrect waren (Erubin 53, Demai 1,3) und dal's die Bemühungen der mischnischen Autoritäten, dem zu steuern, wie die neuhebräische Grammatik beweist, vergebliche waren. Die neuhebräische Lautlehre zeigt 
durchgehende Verwechselung der Hauche; dasselbe begegnet uns bei den hellenistischen Juden, s. Frankel S. 101.110 u. a. und m. philon. Studien (in Merx Archiv f. w. Erf. des A. T.'s Bd. 2, S. 150). Hieronymus hat also die Verwirrung nicht hineingebracht, sondern vorgefunden. Auch hat er wohl gewufst, dafs es eine solche sei, wie hervorgeht aus de nom. hebr. (Lag. on. s. I, 2, 4-14) : non statim ubicumque ex A. littera, quae apud Hebraeos dicitur aleph, ponuntur nomina, aestimandum est ipsam esse solam quae ponitur. nam interdum ex ain saepe ex he nonnunquam ex heth litteris, quae adspirationes suas vocesquae commutant, habent exordium. Sciendum igitur quod tam in Genesi quam ceteris in libris ubi a vocali littera nomen incipit apud Hebraeos diversis inchoetur elementis, sed quia apud nos non est vocum tanta diversitas simplici sumus elatione contenti; unde accidit ut eadem vocabula quae apud illos non similiter scripta sunt nobis videantur in interpretatione variari.

Die Hauchlaute sind ihm im Allgemeinen also Vocale von sehr unsicherem Charakter, doch zeigt der Zusatz (adspirationes suas ... commutant), dafs er wohl weifs, dafs sie auch Hauche sind. (Vgl. auch epist. 125 ad Rust. c. 12 cuidam fratri qui ex Hebraeis crediderat me in disciplinam dedi ut ... stridentia anhelantiaque verba meditarer.)

§6. $\aleph$ gilt ihm zwar wie aus der eben angeführten Stelle hervorgeht principiell als der Vocal a, vertritt aber in Wirklichkeit wie bei den LXX (vgl. Frankel S. 107)

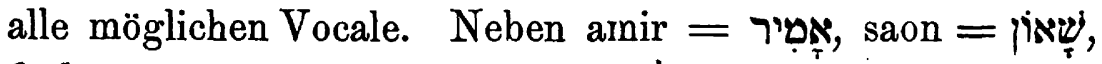

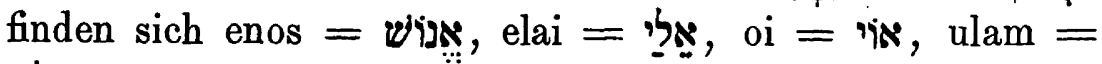
אוּ א. a. Im Auslaut gilt $\aleph$ als blofser Dehnbuchstabe des Endvocals : z. B. hu $=$ הווּא, ge $=$, gi $=$ Im Anlaut wird es bisweilen als Hauch gehört (vgl. bei den

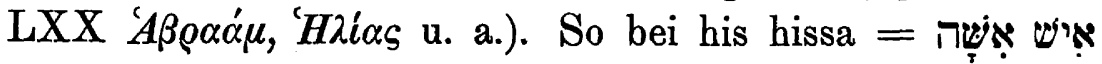
quaestt. in Gen. p. 6, 5. 6; selbst im Inlaut in raha $=$ 


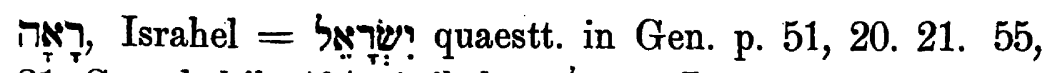
21, Samuhel ib. 104, Arihel = אִרִיֵֵל Lag. on. s. I, 3, 15.

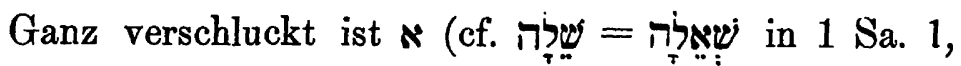

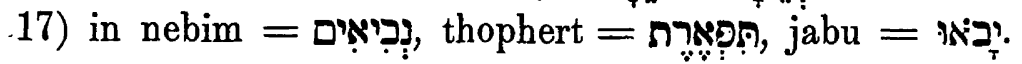

§ 7. $ה$ gilt ebenfalls principiell als ein Vocal. So im

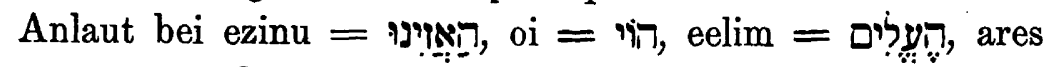
$=$ הֶֶ, aadam $=$

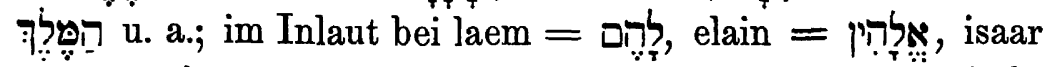
$=$ ירָּר

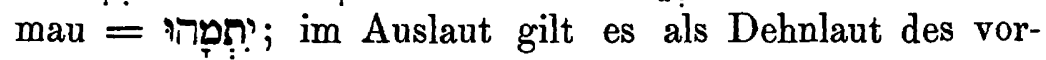

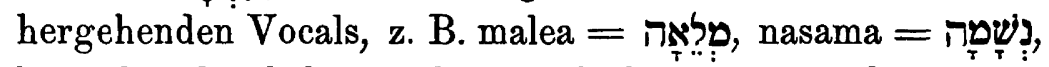

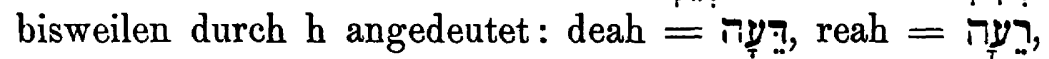

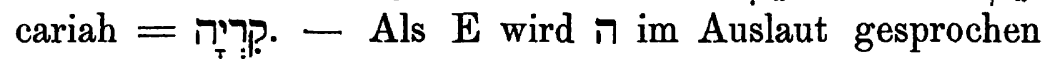

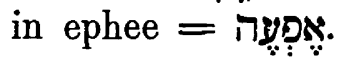

Seltsam ist die durch Hieron. eigene Transscription in den obigen und vielen anderen Beispielen (s. Index) mit ihrem wechselnden Vocalismus widerlegte Theorie, in der er quaestt. in Gen. p. $27 \mathrm{i}$ dem Vocal e gleichsetzt und zu dem abenteuerlichen Auskunftsmittel greift : „idioma enim linguae illius est per $\mathbf{E}$ quidem scribere sed per $\mathbf{A}$ legere." Man könne daher dieser Einrichtung zufolge schreiben und Abraam sprechen.

Indessen findet sich trotzdem $\pi$ auch einige Male als Hauch wiedergegeben. Vielleicht hat hier das Schwanken des Spätlateinischen zwischen Aussprechen und Fortlassen des Hauchs wie in Hoctober, October, oder honor, onor (vgl. Schuchardt I, 18. 75) eingewirkt. So schreibt Hieron. hod = הוֹ, hin, heres $=$

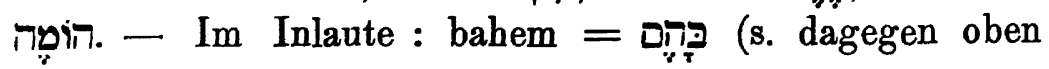
laem).

Wie bei $*$ so finden sich auch bei $\boldsymbol{i}$ einzelne Fälle, in denen dasselbe in der Aussprache ganz verschluckt ist.

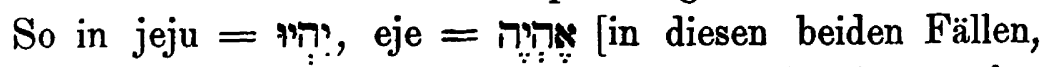
weil eben das $i$ als e ausgesprochen wurde], aber auch : 


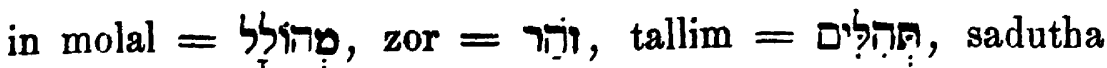
$=$ = שִּרה

$\S 8$. Auch $y$ ist nach der oben $\S 5$ angef. Stelle ein Vocal, vgl. auch V all. VI, 24 C, wo er es vocalis litera nennt.

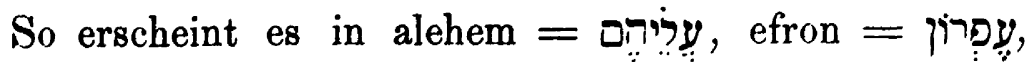

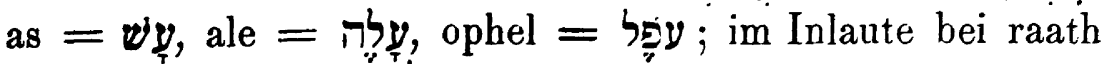

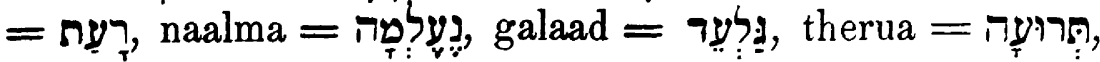

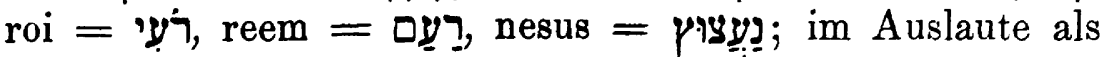

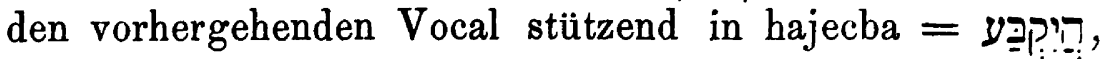
ana $=$ הנֵ , bisweilen auch selbständig als e lautend : z. B.

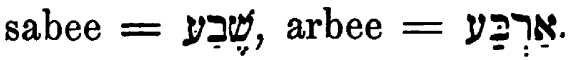

Ganz verschluckt ist $\boldsymbol{y}$ in mrim $=$ עִ מרעy $\operatorname{mosim}=$

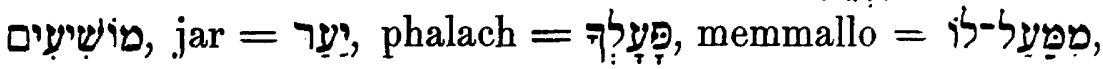

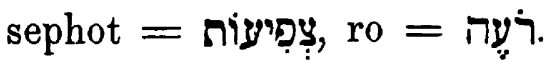

Eine Ausnahme bildet Gomorra, die aber den Hieron. trotzdem an seiner vocalischen Theorie nicht irre macht. Er sagt : de nom. hebr. (b. Lag. on. s. I, 6, 28. 29) sciendum quod $g$ litteram in hebraico non habet, sed scribitur per vocalem $y$.

§ 9. $\pi$ gilt ebenfalls principiell als Vocal : wie oft bei LXX (s. Frankel S. 109). So in adrach = חדרדרךְ

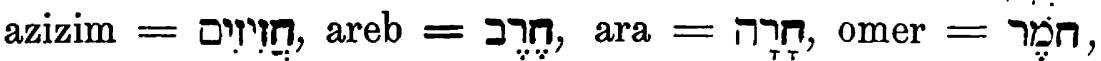

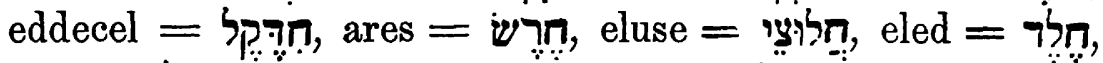

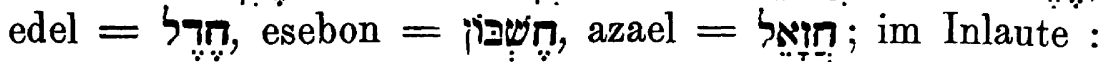

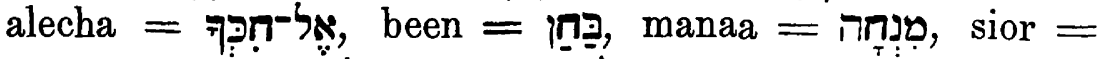

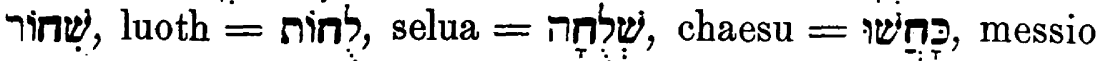

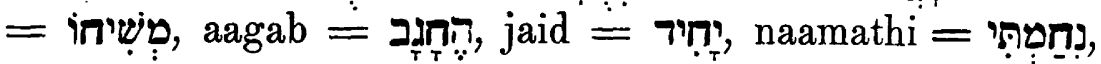
aad $=$ רִ̣.

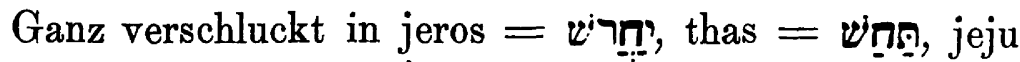
$=$ = נֶֶֶ, maphete =

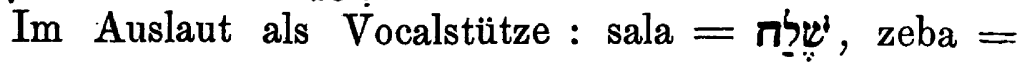

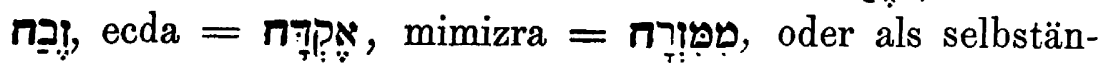
diger Vocal tönend : mesphaa $=$ = מִִ̣ 
Indessen kennt er $\boldsymbol{\pi}$ auch als Hauch : quaestt. in Gen. p. 13 heth litera duplicem aspirationem sonat; de nom. hebr. (Lag. on. s. I, 4, 10--12 zu Cham) sed sciendum quod in hebraeo $\chi$ literam non habeat, scribitur autem per $\pi$ quae duplici adspiratione profertur. Er giebt es daher oft durch $h$ wieder, welches dem griechischen spiritus asper entspricht (Corssen I, 112). So in hatath = חַ

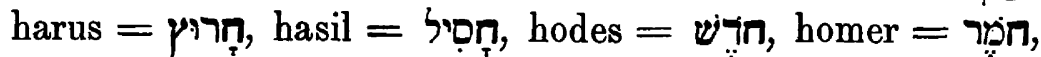
hazon $=$, homa $=$ iñin ; im Inlaute $:$ iaeahamena $=$ אוֹ,

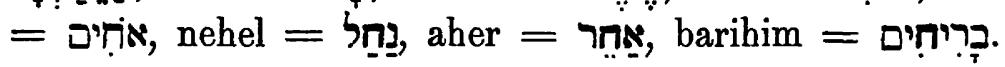

Durch ch ist $n$ wiedergegeben in cham $=\Delta \pi$, desgleichen bei Chettaeus (in de nom. h. on. s. I, 4, 18-20), Charran (ib. 1, 4, 21. 22), Chebron (ib. 23. 24), Chaber (ib. I, 5, 2.3), wobei jedesmal bemerkt ist, dafs im Hebräischen ein $\boldsymbol{n}$ stehe.

\section{d) Spiranten (Vocalbuchstaben) I, '.}

Obwohl er sie als Vocale bezeichnet (quaestt. in Gen. p. 27, 17. 36, 10 u. a.), behandelt er sie doch thatsächlich bisweilen als Consonanten.

$\S 10$. I im Anlaut wird, wenn ohne vollen Vocal, bei

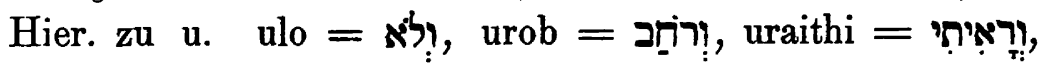
bei folgendem Vocal consonantisch und mit diesem verschmolzen : vasam = וֹאָָ - Im Inlaut ist es wechselnd $\boldsymbol{v}$ und $u$. Das lateinische $\mathbf{v}$ wird wie deutsches $w$ gesprochen (Corssen I, 323), doch oft kaum gehört vgl. paimento st. pavimento (Schuchardt I, 24). So : ava $=$ =

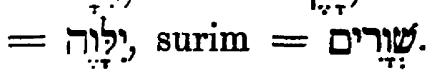

Im Auslaut ist $\mathrm{I}$ Tִ $=$ u. elau $=$ (Ezech. 40, 16),

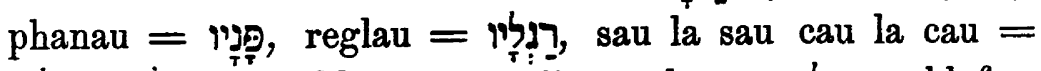

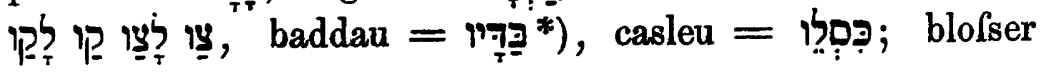

*) In allen diesen Fällen scheint der lateinische Diphthong au ge- 


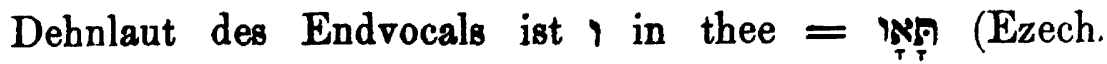
40,21 ).

Im Inlaut vocalisirt ist 1 in onam yִ

$\S 11$. ' ist im Anlaute, wenn volle Vocale folgen, in der Regel Consonant :

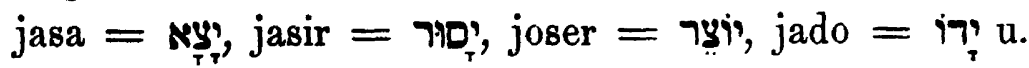
viele andere : s. den Index.

Seltener ist es im Anlaut Vocal in diesem Falle, wie

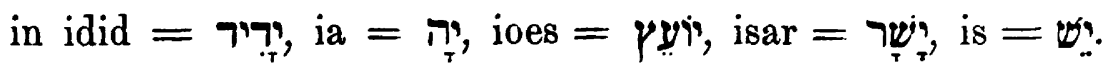
- Wenn dagegen Sba mobile folgt ist, stets vocalisch : wie bei igar = ?יר:, idabber $=$, ior $=$, isurun $=$ = שור

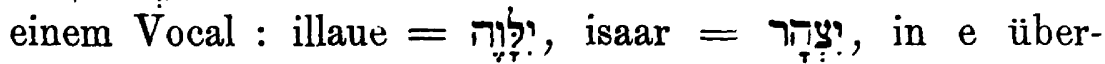
gehend in eje = ידי (b. V. VI, 932 D), mit nachschlagendem e : iezbuleni $=$ =

Im Inlaut ist es bisweilen Consonant wie in haja = , היזה, jeju = in der weit überwiegenden Mehrzahl der Fälle wird es vocalisch wie in cariah pִ pegionoth

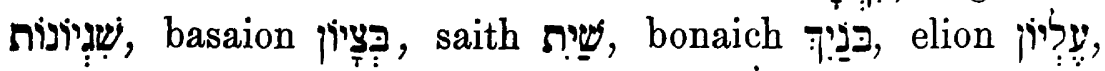

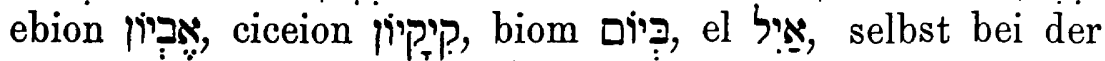

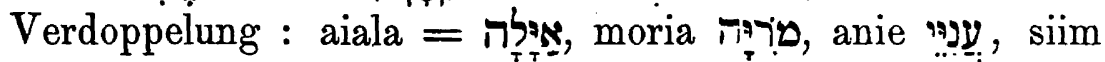
םצ्. - Eigenthümlich sind einzelne Fälle mit nachklingendem a im Inlaute wie sariagim Gִ שָרִיִגים Ganz verschluckt

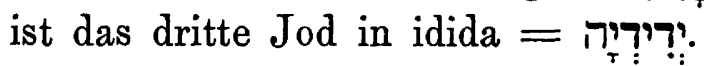

Im Auslaut ist, Vocal :

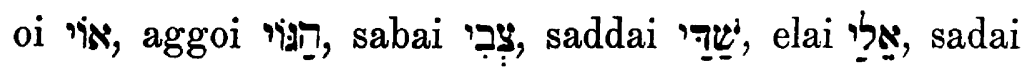

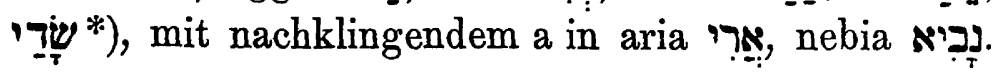

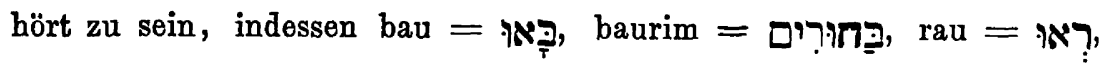
jadau $=$ I worden ba-u, ba-urim, ra-u, jada-u, jethma-u.

*) Da die Lateiner die Diphthonge ai, ei und oi nicht kannten, so liegt die Sache hier anders als in den analogen Fällen von $\S 10$. Schwerlich hat Hier. raim, leis, reim, roi, sondern ra-im, le-is, re-im, ro-i gesprochen. Auch in solchen Fällen, wo bei ae die Vocale durch 
e) Die Verdoppelung der Consonanten.

$\S 12$. Sie ist bei Hieron. in zahlreichen Fällen ausgedrückt : z. B. semmathech

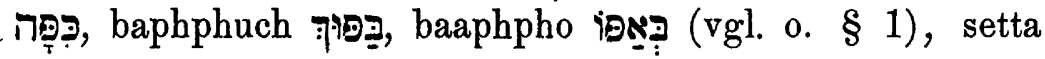

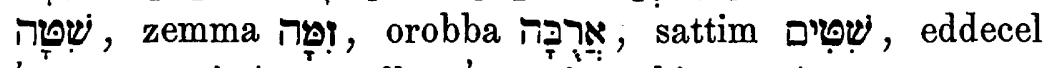

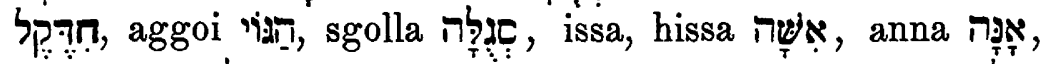

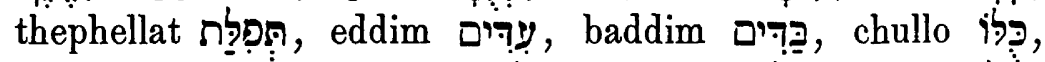

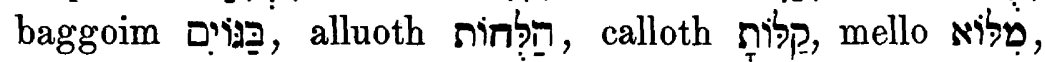

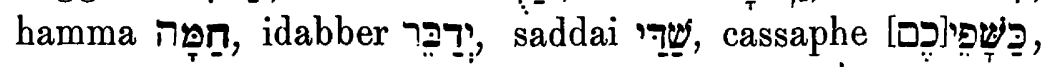

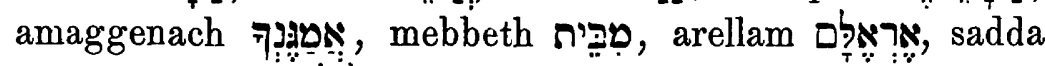

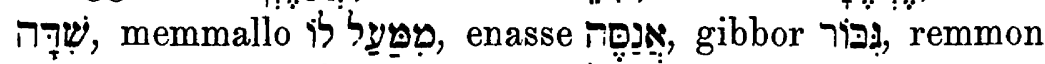

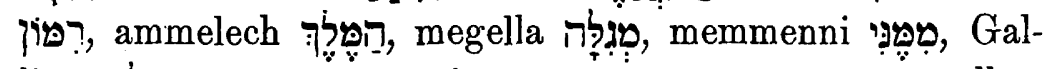

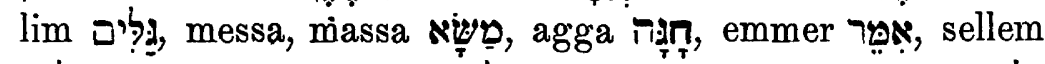

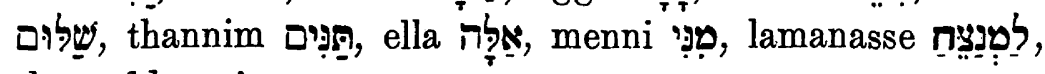

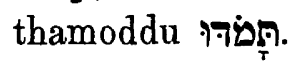

Sehr häufig aber findet sich die Verdoppelung nicht

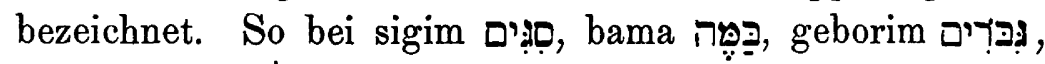

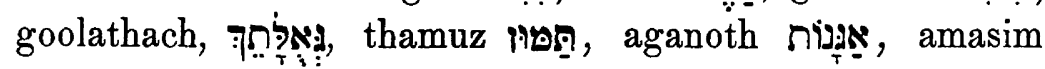

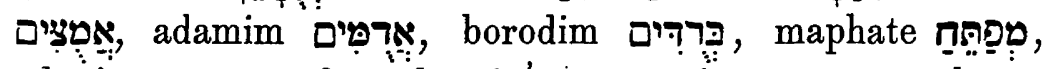

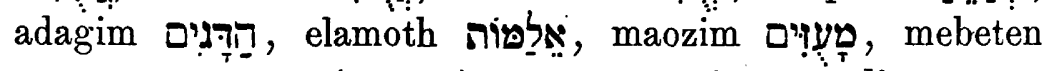

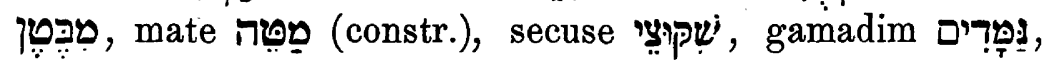

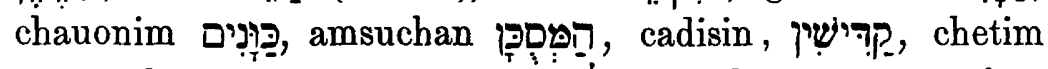

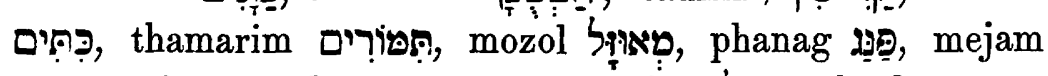

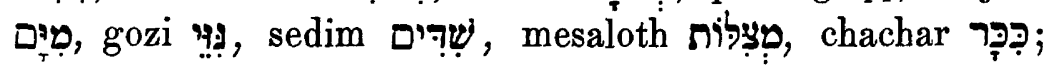

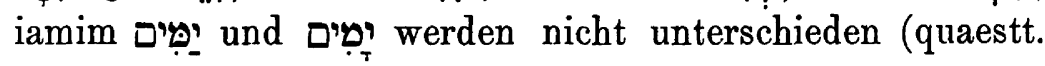
h. p. $55,19.56,26)$.

Bisweilen läfst Hieron. Verdoppelung eintreten, um den kurzen vocalischen Anlaut der Worte (besonders Sba mobile) zu markiren :

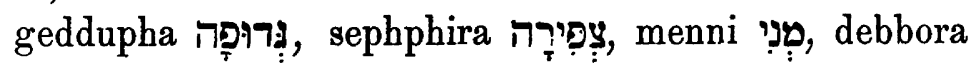

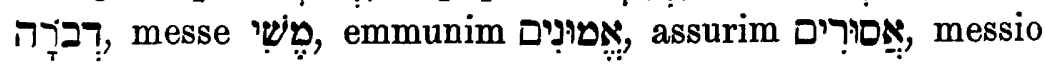

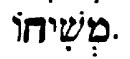

einen Hauch getrennt waren, sprach er wohl a-e, wie in carae קרָר

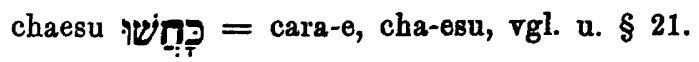


In Füllen wie : gessemanim sarim טַecheint die damalige Aussprache das assimilirt zu haben, ebenso scbeint in aphpho אִ eine Art cuphonisches Dagesch zu Gruprle zu liegen. Auffällig ist jaccum klüren.

Durch Nichtbeachtung der Verdoppelung sind bisweilen

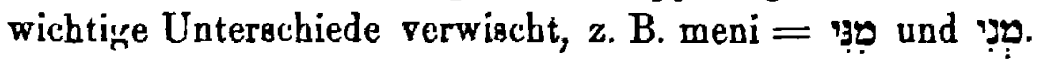

\section{Die Vocale.}

a) Die vollen Vocale.

$\S 13$. Wenn Hieron. lange und kurze. Vocale in der Transscription nicht unterscheidet, so hat dies seinen natürlichen Grund darin, dafs dies im Lateinischen überhaupt nicht gesschah. Dafs er thatsächlich den Unterschied derselben kannte, zeigen seine Zusammenstellungen, die er bei den vocalisch anlautenden Worten hinsichtlich der Kürze und Länge in de nominibus hebraicis macht, s. z.B. b. Lag. on. s. I, 5, 28. 29 „huc usque per brevem litteram E nunc per productam nominum sunt legenda principia “, vgl. auch p. $9,14.15$. 12, 30. 31. 14, 16. 17. 18, 3. 4. 19, 24. 25 u. a. Freilich widerfahren ihm dabei Irrthümer, wie z. B. p. 6, 1. 6 Elisa u. Elifaz unter den Worten mit langem $\mathrm{E}$ aufgeführt sind.

\section{A - L a u t e.}

$\S 14$. Was die einzelnen Vocale anlangt, so werden Kamez und Pathach gleichmälsig durch a wiedergegeben :

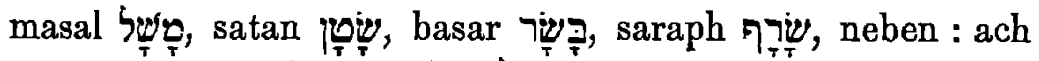

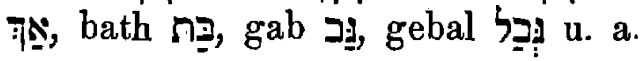

Dafs aber Kamez nicht immer damals als reines â gelautet hat wie im Lateinischen (Corssen I, p. 324), sondern dafs öfter die Aussprache a gehört wurde [wie die-

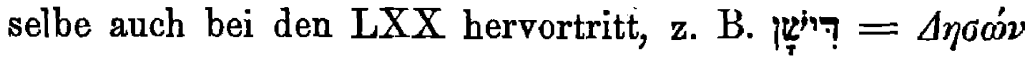


u. a. (s. Frankel S. 115), vgl. für Philo Delitzsch, Jesurun S. 92 und meine philon. Studien in Merx' Archiv

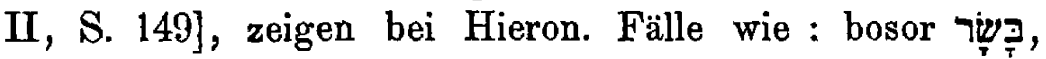

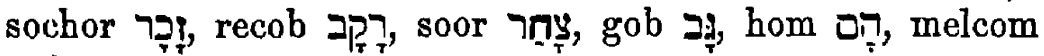

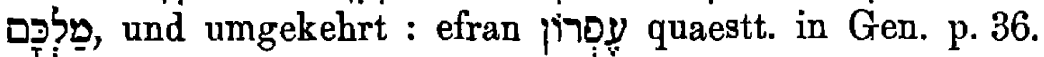
- Uebrigens trat auch im Spätlateinischen diese Verunreinigung des Lautes ein : Schuchardt I, 32 führt das Beispiel eines Reiurs dono auf annona an.

Abweichend vom MT. sind einige Worte statt mit $\hat{a}$ mit ê gesprochen.

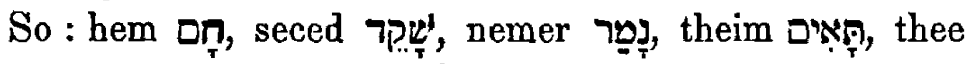

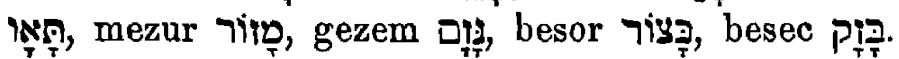

Desgleichen steht oft $\breve{e}$ für $\breve{a}$, wie in LXX s. Frankel S. 117 (vgl. für dies Schwanken'im Lateinischen : lucarna $=$ lucerna ; lacartus $=$ lacertus $\mathrm{s} . \mathrm{Sch}$ uchard $t$ I, 29) :

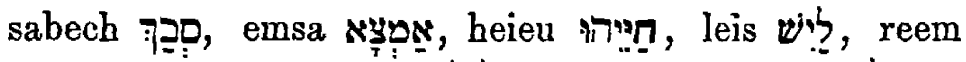

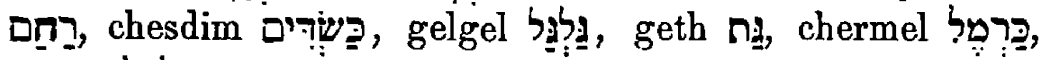

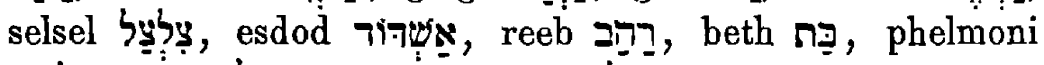

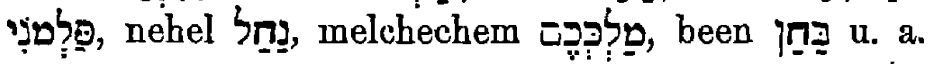

Besonders auch vor der Verdoppelung : sellem 머리,

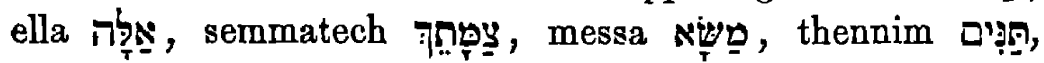
adadremmon הריר:

Dem Schwanken von $\hat{a}$ zu a entsprechend finden sich auch einige Beispiele vom Uebergang des $\breve{a}$ in $\breve{~}$ (bei LXX

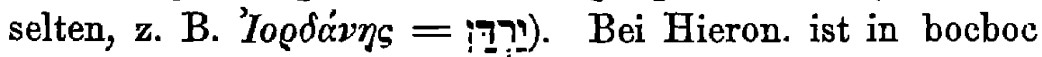

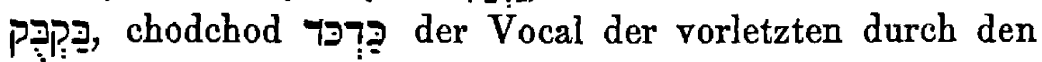
Endrocal beeinflufst, anders ist es in mosechim Pㄱ, rob ברา.

Selten ist $\mathrm{i}$ statt a : sinthoroth תצִ

$$
\text { E - L a u t e. }
$$

$\S 15$. Sfsere ist bei Hieron. e.

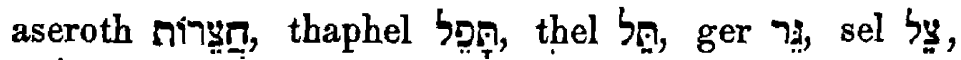

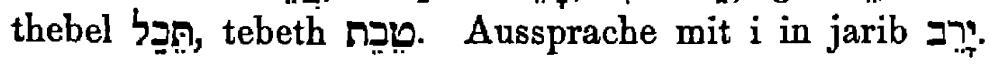


Manche Worte, die im MT. mit - vocalisirt sind, werden bei $\mathrm{H}$. mit a ausgesprochen.

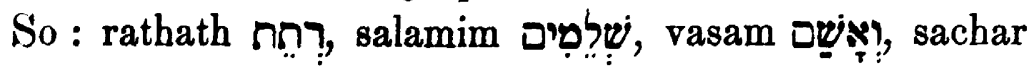

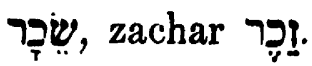

Wie bei LXX '- bisweilen durch $a \iota$ wiedergegeben

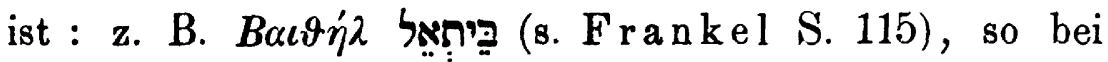
Hieron. durch ae in nugae, was freilich auf seiner seltsamen Gleichsetzung beider Worte beruht (VI, $730 \mathrm{~B}$ ), vermöge deren er folgert linguam Hebraicam omnium linguarum esse matricem.

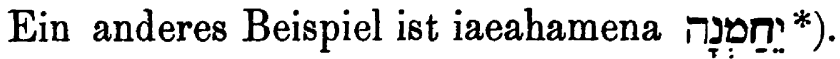

Ueber den Laut dieses ae im Griechischen und Lateinischen und seine Entwickelung s. Blafs S. 13.

Segol und Sfsere werden in der Bezeichnung von $H$. nicht unterschieden; doch läfst sich daraus nicht folgern, dals dies auch in der Aussprache nicht geschehen sei.

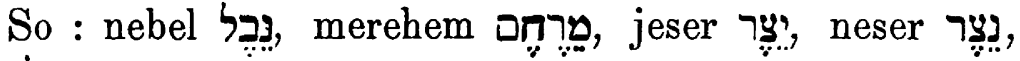

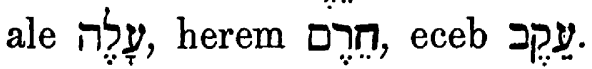

Bei einigen Worten scheint der Lehrer des $\mathrm{H}$. a gesprochen zu haben, wo MT. Segol hat.

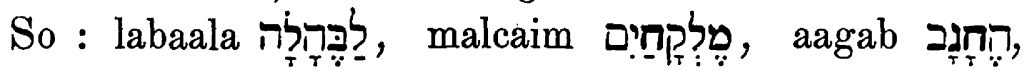
cesath קִקְ:

In der Wiedergabe der sogen. Segolatformen herrscht grofses Schwanken.

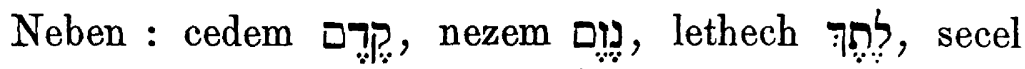

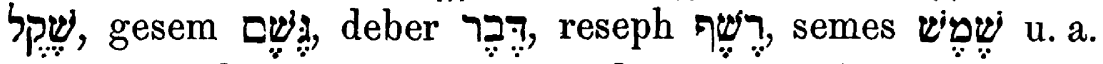

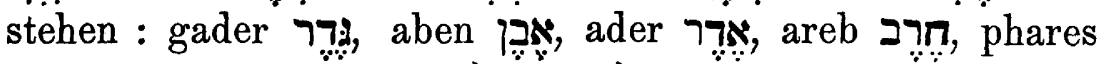

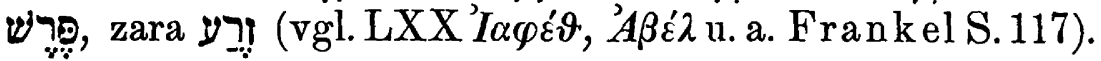

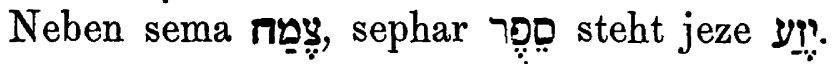

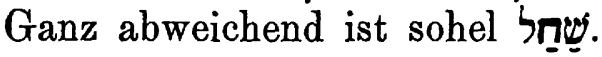

Infolge der damals schwindenden Aussprache der Hauchlaute werden manche Segolate mit Hauchen einsilbig

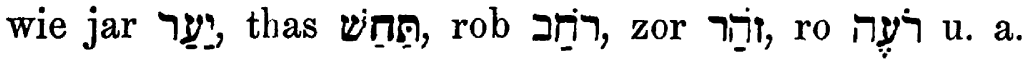

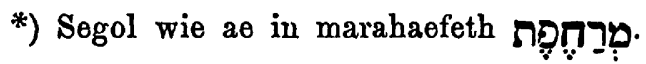




\section{I - L a u t e.}

§ 16. Chirek magnum wird fast durchgehend durch i wiedergegeben (seltene Ausnahme mit ei*) in eis = אִ), namentlich lautet die Pluralendung ים- durchweg -im; s. den Index.

Dagegen hat sich das kurze I nur in seltenen Fällen

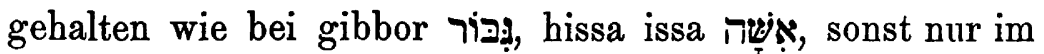
Anlaut, wo es bei Hieron. an die Stelle des Sba mobile

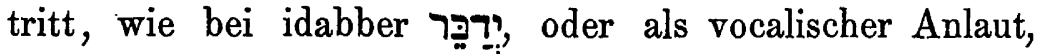
vgl. o. § 11 .

In allen anderen Fällen ist das kurze I durchweg in ě oder a übergegangen (vgl. den ähnlichen Uebergang bei den LXX Frankel S. 118. 119).

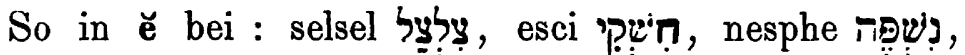

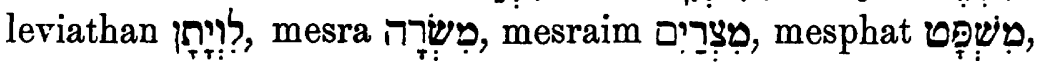

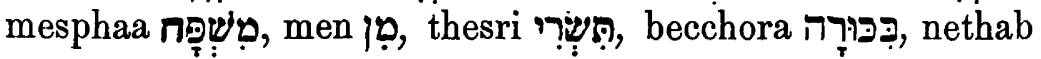
נִִ uִ u. a.

Namentlich fast immer vor der Verdoppelung : emmer

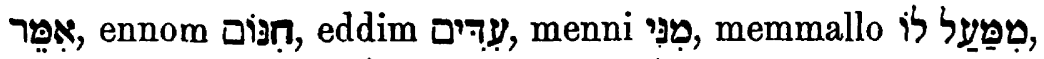

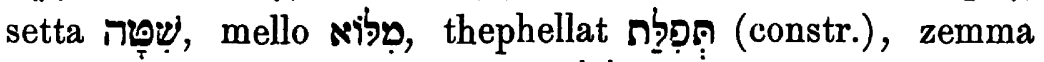

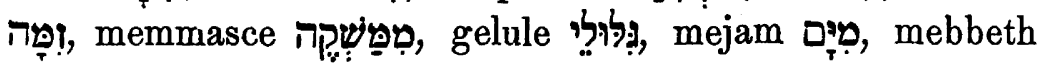
טִבֵּית u. a.

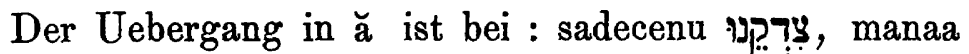

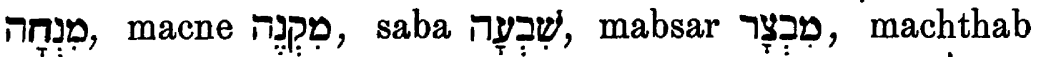

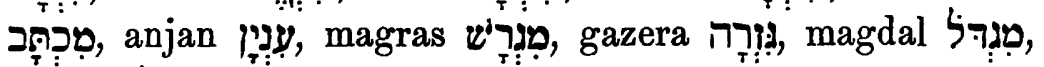

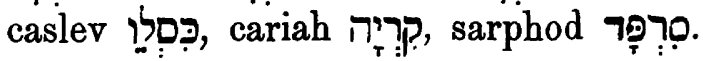

Vor Verdoppelung bei : sadda שְִִִׁ̣, sattim san-

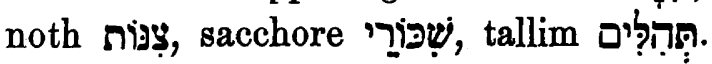

$$
\text { O- und U-Laute. }
$$

$\S 17$. I als Vocal wird u oder o gesprochen, vgl. bei V. VI, $366 \mathrm{C}$ vau quippe littera et pro $\mathfrak{u}$ et pro o eorum

*) Vgl. über die schwankende Schreibung ei, i, ө im Lateinischen Blafs S. 20. 
lingua accipitur; quaestt. in Gen. p. 36 vau litera quae apud eos pro o legitur. So findet sich masor neben masur für רฺָּ

So wechseln auch für Cholem plenum und defectivum die Schreibungen o mit denen in $u$.

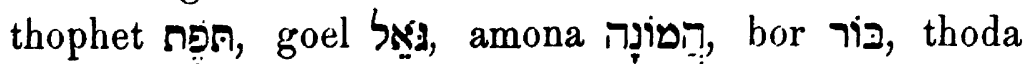

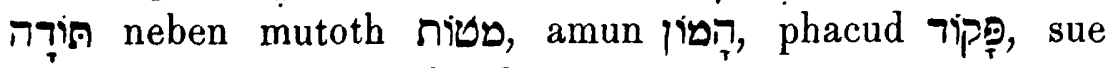

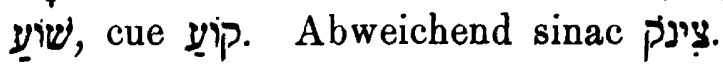

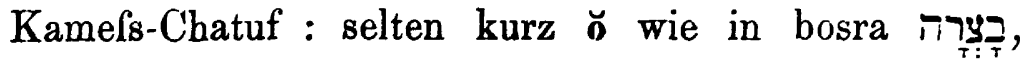

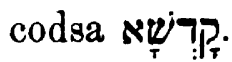

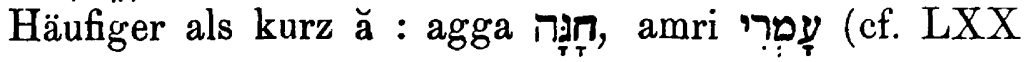
"A $A \mu \beta \varrho \iota)$, cadeso

Shurek ist $\mathrm{u}$ oder 0 .

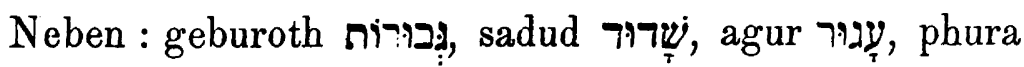

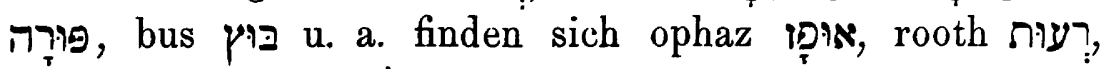

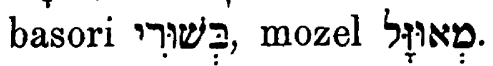

Ueber das Schwanken von $u$ und o in der spätlateinischen Volkssprache s. Corssen I, 343. Wir können daher nicht wissen, ob hier die hebräische oder die lateinische oder vielleicht beide Aussprachen schwanken.

Durch die schwankende Lesung von Waw und Jod*) kommen auch differente Aussprachen. So bei : aelam

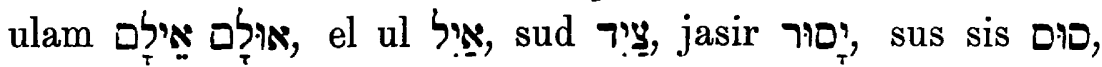

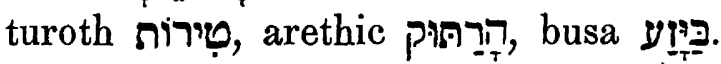

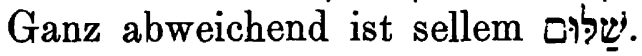

Kibbufs scheint selten ganz deutlich gehört worden zu

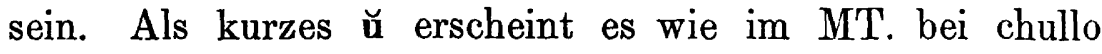

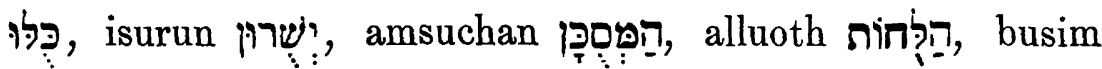

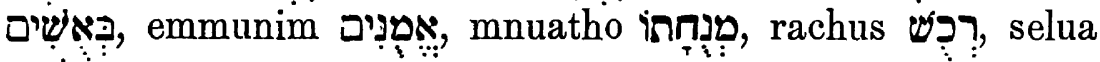

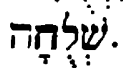

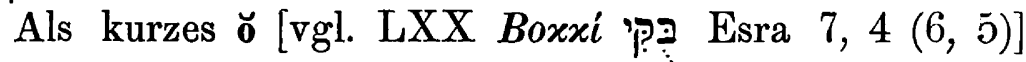

*) „ut quia Vav et Jod literae eadem forma sed mensura diversae sunt altera legatur pro altera" (Vall. V, $818 \mathrm{~B}$ ). 


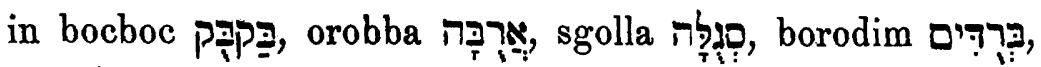

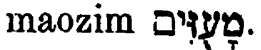

Als kurzes a in chasamim

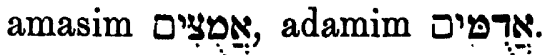

$\mathrm{Zu} \mathrm{Sba} \mathrm{mobile} \mathrm{verkürzt} \mathrm{in} \mathrm{:} \mathrm{atemoth} \mathrm{תivọ,} \mathrm{phetee}$ คกฺฺฺฺุ

\section{b) Die Halblaute und die Nachklänge.}

$\S$ 18. Chatef pathach wird durch a ausgedrückt in :

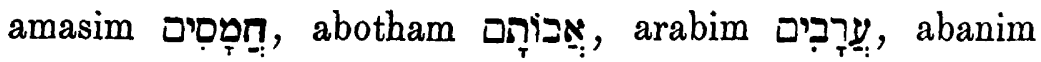

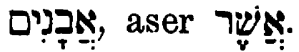

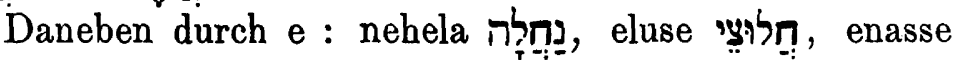

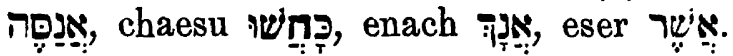

Durch б : orobba אִ: (Gleichmachung der Laute.)

Chatef segol : durch e wiedergegeben :

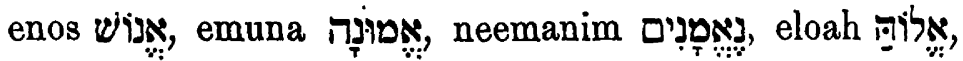

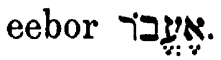

§ 19. Pathach furtivum : nachklingend bei ruha 께, vorschlagend bei ruah, colea yלp, als è nachklingend (wie

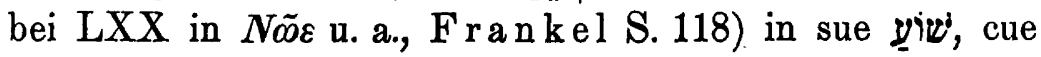

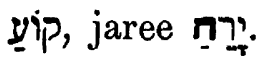

Sehr häufig geht dieser Nachklang verloren. So in

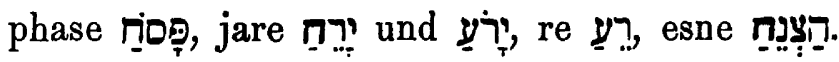

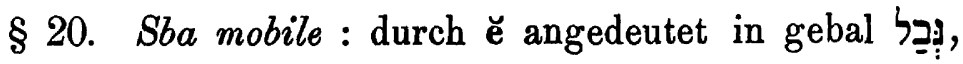

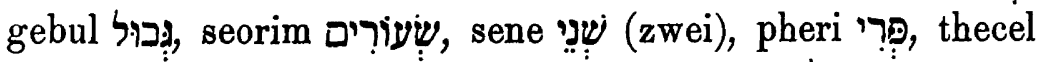

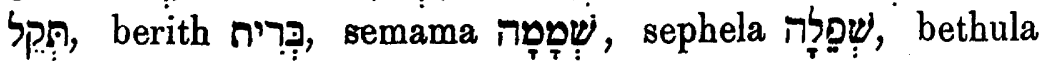

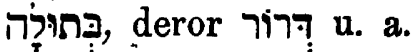

Sehr oft aber durch ă, welches meist durch folgenden A-Laut bestimmt ist (vgl. LXX b. Frankel S. 121) wie

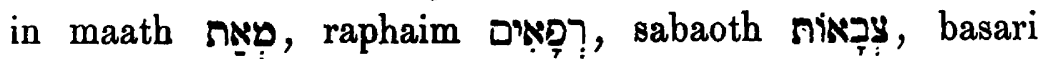

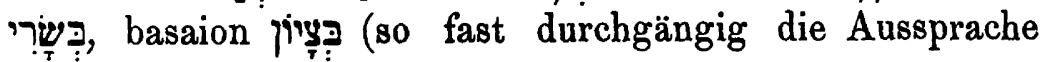
der praepos. $\underset{Z}{Z}=\mathrm{ba}$ ), baaphpho

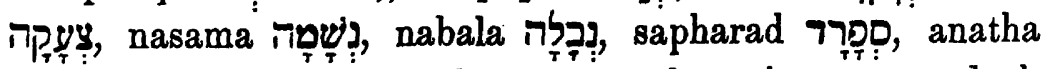

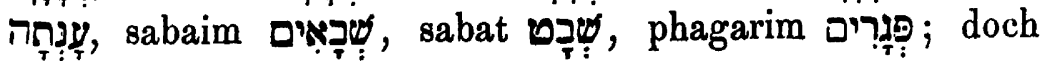




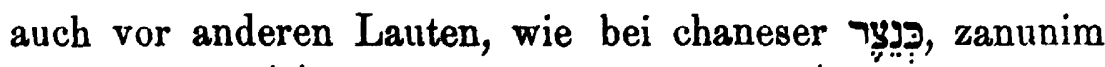

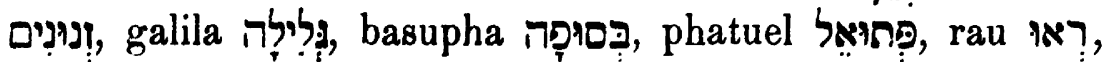

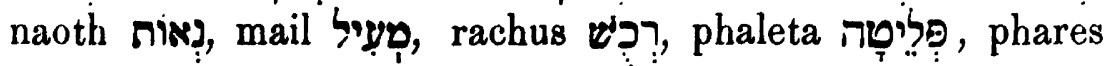

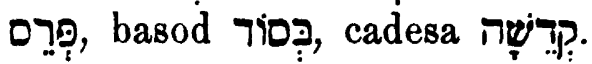

Vereinzelt als o in chorethim פִּרִתִים, wo aber vielleicht gִ כִרִתִים gelesen ist.

Oft wird das Sba mobile dem folgenden Laut ähnlich gemacht wie in chisileem נְִִּלִים

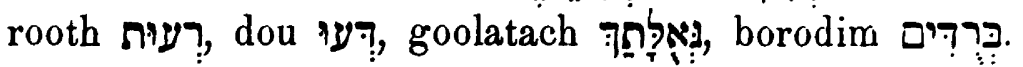

Doch geschieht es nicht immer, z. B. baemunatho

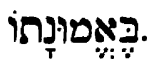

Bisweilen wird namentlich das anlautende Sba mobile

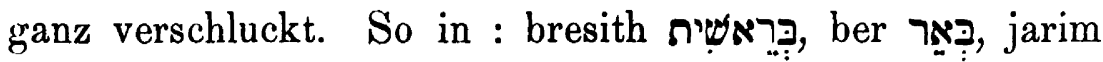

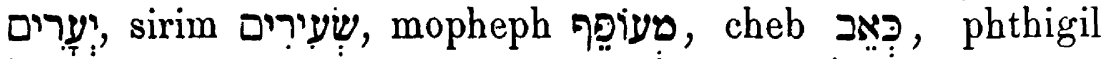

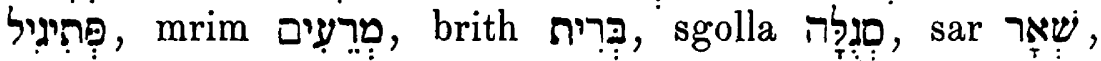

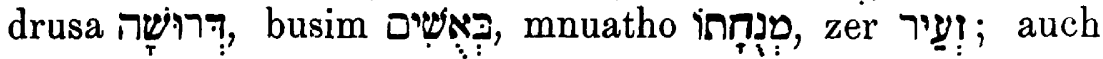

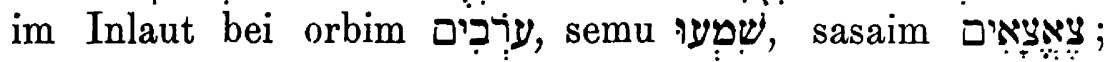
lautbar dagegen ist es in mozene מאוּנִ (Sba medium, Ewald).

Ueber die Markirung des anlautenden Sba m. durch Verdoppelung s. o. $\S 12$.

In einigen Verbalformen ward statt des Sba mobile der Charaktervocal der Tempusform gesprochen, z. B.

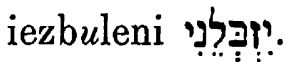

§ 21. Auch für Sba quiescens tritt öfter ein leiser Nachklang ein :

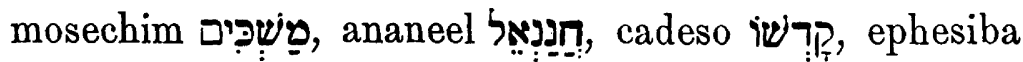

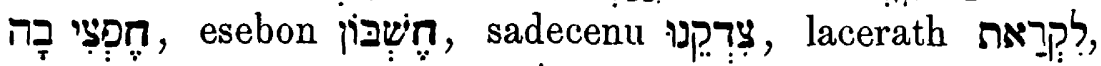

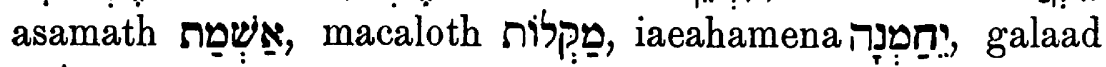

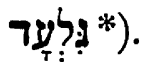

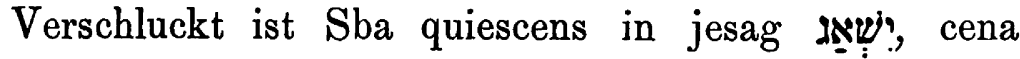

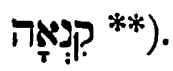

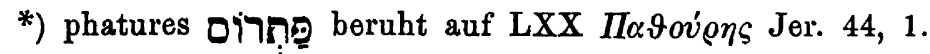

**) Das Zusammenstolsen zweier Vocale (der Hiatus) wird in der lateinischen Transscription des Hieron. bisweilen vermieden. So in den 
Bei der Feststellung des Urtheils über die Aussprache des Hebräischen, wie dieselbe dem Hieronymus von seinen Lehrmeistern beigebracht wurde, ist aber Folgendes zu erwägen :

1) Diese Aussprache war keine ganz constante*). wird einmal durch is, das andere Mal durch his, endlich durch eis umschrieben. - הרים durch heres und ares. - חֶלֶ durch holed und eled. - חֶֶר durch homer und omer. - Unwesentlich sind die Schwankungen in der Wiedergabe des $₫$ durch ph und $f$, welche zum Theil auf Fehlern der Handschriften beruhen (vgl. § 1).

2) Ebenso war die Vocalaussprache schwankend: wird basar und bosor umschrieben, ebenso ș

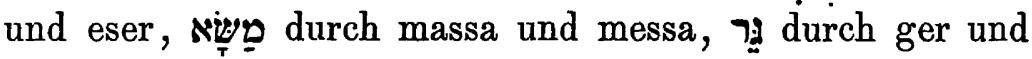

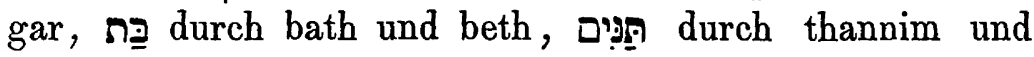
thennim, vgl. auch $\mathrm{Nowack}$, S. 43-48. Dies hatte zur Folge, dals manche Worte nicht ordentlich auseinander-

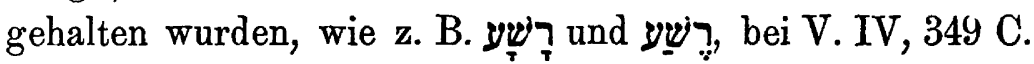

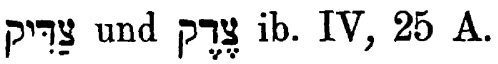

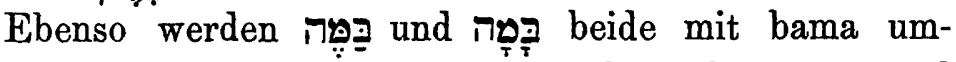

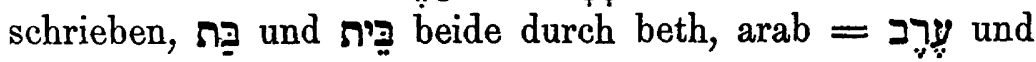

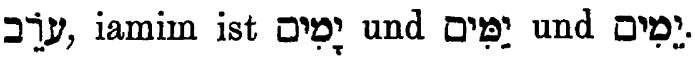

3) Eine schlimmere Quelle der Verwechselungen war die mangelhafte Unterscheidung der Hauchlaute und der Zischlaute, der einfachen und der Doppelconsonanten.

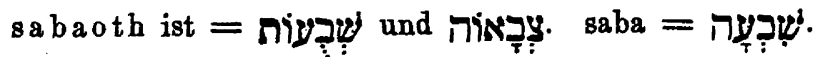

assur

Schreibungen : Israhel (quaestt. h. p. 13, 33 psalter. ed. La g. p. 121. 133. 134 u. o.), Samuhel (psalter. p. 104), Ismahel (quaestt. h. p. 26, 13), Fanuhel (ib. p. 52, 29) u. a. Doch geschieht es nicht immer : s. z. B. eloim (quaestt. h. p. 11, 23), roim, iogs u. viele andere.

*) Wobei aber zu beachten, dafs bei keiner Sprache der Welt die Aussprache etwas Constantes ist. So lange die Sprache lebt wechselt jene mit dieser. Und bei der todten Spracho wechseln die Ueberlieferungen.

Zeitschrift f. d. alttest. Wiss. Jahrgang 4. 1884. 


\begin{tabular}{|c|c|c|c|}
\hline $280 r$ & ist $=$ & 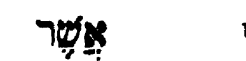 & 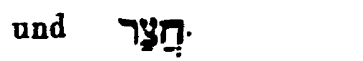 \\
\hline jare & $n=$ & ירום & 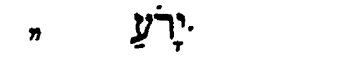 \\
\hline asamim & $n=0$ & חְטָספים & 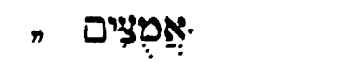 \\
\hline arim & $n=$ & דֶרִים & •עָרים \\
\hline $\operatorname{sad} \theta$ & $n=$ & שָׁרָה & צִּרָא \\
\hline$h$ is & $n=$ & אִישט & חית. \\
\hline phares & $n=$ & 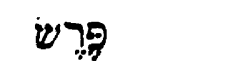 & •פְרִס \\
\hline ares & $n=$ & חֶֶרש & 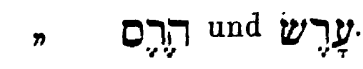 \\
\hline jeju & $n=$ & יְִּיוּוּ & יְְִּיוּי \\
\hline aphpho & $n=$ & אַפטֹן & אַףר־הוּא ח \\
\hline is & $n=$ & אִִישט & $n \quad$ יש: \\
\hline homa & $n=$ & חעָin (Mauer) & ח הוֹמֶֶה (brausend). \\
\hline sara & $n=$ & עַזזרדה ה & 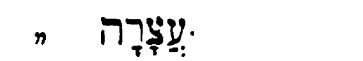 \\
\hline
\end{tabular}

Hieronymus hatte demnach auf seinem Standpunkte hinreichenden Grund von der ambiguitas hebraici sermonis zu sprechen.

Dies gab in den vielen Fällen, wo Hieron. den Grundtext nicht näher ansah, Veranlassung zu Irrungen. So wenn hareb mit siccitas corvus und gladius gedeutet wurde,

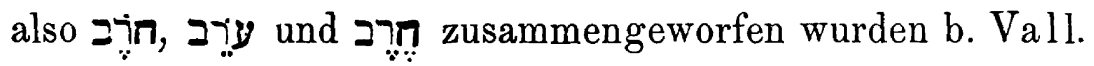
VI, 710 A. Oder wenn de nomin. hebr. (on. s. I, 19, 16) Noa mit motus übersetzt, also an yil gedacht wird. Und so in zahlreichen Fällen, deren Verfolgung aufserhalb unserer Aufgabe liegt. Einiges ist zusammengestellt bei Nowack S. 6-10; doch verdient Hieron. nicht Tadel, dals er manches nicht wulste, was wir wissen, sondern Bewunderung, dals er so viel wufste, wie zu seiner Zeit und lange nachher Niemand in der christlichen Kirche.

4) Wenn aber auf diese Art vieles verwirrt wird, so ist doch darauf aufmerksam zu machen, dals die damalige Aussprache des Hebräischen auch wiederum Manches unterschied, welches wir zusammenwerfen. So unterscheidet

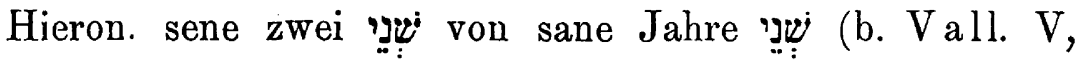


$141 \mathrm{D}$ si legatur sene duo significat si sane annos). ?ר als status absolutus ist zara, als st. constr. zera z. B. Jes.

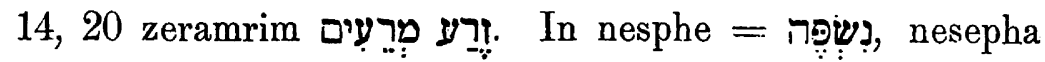
$=$ = einandergehalten.

Eigenthümlich ist die Spur einer Aussprache mit Nuna-

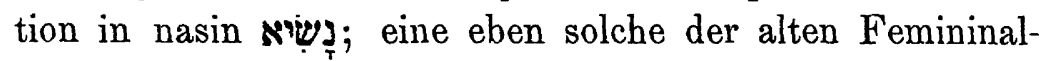
endung $\Omega$ - in der 2. Person des Perfects in carathi st.

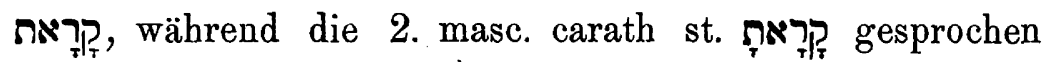

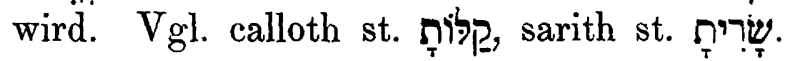

Die Erhaltung vollerer Vocale beim Verbo findet statt

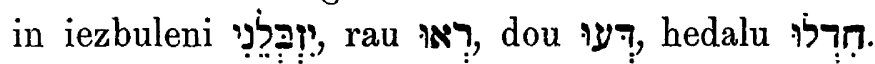

Die Aussprache des Pronominalsuffixes des 2. Masculini in $7_{\bar{T}}$ amaggenach

\title{
Die Composition des Buches Jesaja.
}

\author{
Von Lic. Dr. C. H. Cornill in Marburg.
}

Die nachfolgenden Zeilen erörtern ein Problem, welches in der mir zugänglichen Literatur über Jesaja bisher noch nicht einmal aufgeworfen ist*), welches aber einer Lösung dringend bedarf - die Frage : Wie ist das Buch Jesaja in der uns jetzt vorliegenden Gestalt als Ganzes zu

*) Die Commentare zu Jesaja und die Einleitungen ins Alte Testament geben nur die Analyse, nicht aber die Synthese, d. h. sie zerlegen das Buch Jesaja wohl in seine einzelnen Bestandtheile und zählen diese auf, sagen und fragen aber nicht, wie diese einzelnen Bestandtheile zu dem uns jetzt vorliegenden Ganzen wurden. Auch Lagarde, welcher Symmicta I, 142, cf. auch Semitica I, 1, eine Gesammtanschauung von dem Buche Jesaja als Ganzes vorträgt, lälst die Anordnung und Reihenfolge der einzelnen Bestandtheile unerklärt. 